\title{
Host Transcriptional Profiling at Early and Later Stages of the Compatible Interaction Between Phaseolus vulgaris and Meloidogyne incognita
}

\author{
Luciane Santini, Carla de Freitas Munhoz, Mauro Ferreira Bonfim Jr., \\ Marcelo Mendes Brandão, Mário Massayuki Inomoto, and Maria Lucia Carneiro Vieira
}

\begin{abstract}
First, second, and sixth authors: Departamento de Genética, Escola Superior de Agricultura "Luiz de Queiroz", Universidade de São Paulo, Piracicaba, Brazil; third author: Departamento de Fitopatologia e Nematologia, Escola Superior de Agricultura "Luiz de Queiroz", Universidade de São Paulo, Piracicaba, Brazil; Empresa Brasileira de Pesquisa Agropecuária, Embrapa Recursos Genéticos e Biotecnologia, Brasília, Brazil; fourth author: Universidade Estadual de Campinas, Centro de Biologia Molecular e Engenharia Genética, Campinas, Brazil; and fifth author: Departamento de Fitopatologia e Nematologia, Escola Superior de Agricultura "Luiz de Queiroz", Universidade de São Paulo, Piracicaba, Brazil.
\end{abstract}

Accepted for publication 3 November 2015.

\begin{abstract}
Santini, L., Munhoz, C. F., Bonfim, M. F., Jr., Brandão, M. M., Inomoto, M. M., and Vieira, M. L. C. 2016. Host transcriptional profiling at early and later stages of the compatible interaction between Phaseolus vulgaris and Meloidogyne incognita. Phytopathology 106:282-294.

The root-knot nematode (Meloidogyne incognita) is one of most devastating pathogens that attack the common bean crop. Although there is evidence that some cultivars have race-specific resistance against $M$. incognita, these resistance sources have not proved effective, and nematodes are able to circumvent the host's defense system. We constructed RNA-seq based libraries and used a high-throughput sequencing platform to analyze the plant responses to $M$. incognita. Assessments were performed at

mapping to the common bean reference genome (G19833) resulted in the identification of 27,195 unigenes. Of these, 797 host genes were found to be differentially expressed. The functional annotation results confirm the complex interplay between abiotic and biotic stress signaling pathways. High expression levels of the wounding-responsive genes were observed over the interaction. At early response, an overexpression of the $\mathrm{N}$ gene, a TIR-NBSLRR resistance gene, was understood as a host attempt to overcome the pathogen attack. However, the repression of heat shock proteins resulted in a lack of reactive oxygen species accumulation and absence of a hypersensitive response. Furthermore, the host basal response was broken by the repression of the ethylene/jasmonate pathway later in the response, resulting in a continuous compatible process with consequent plant susceptibility.
\end{abstract} 4 and 10 days after inoculation corresponding to the stages of nematode penetration and giant cell development, respectively. Large-scale transcript
Additional keywords: plant-pathogen interaction, RNA sequencing.
The common bean (Phaseolus vulgaris) is a crop of economic importance and social significance worldwide for boosting the food supply and is a good alternative for reducing hunger, especially in developing countries (Broughton et al. 2003; CIAT 2013). In Brazil, which is the third largest global producer and the second largest consumer (FAOSTAT 2013), it is also an important crop, and the growing season is almost year-round in diverse environments.

Meloidogyne incognita and $M$. javanica are devastating pathogens that attack the common bean crop affecting productivity (Di Vito et al. 2004; Santos et al. 2012). Nematodes account for $90 \%$ of losses in common bean production (Abawi et al. 2005) since they capture host nutrients rendering plants more susceptible to biotic and abiotic stresses (Caromel and Gebhardt 2011).

$M$. incognita is a sedentary endoparasite that requires a plant host to complete its life cycle. Second-stage infective juveniles $\left(\mathrm{J}_{2}\right)$ invade plant roots and move intercellular toward the root tip and make a U-turn into the vascular cylinder, where feeding sites or giant cells are developed (Kyndt et al. 2013). Each $\mathbf{J}_{2}$ induces differentiation of five to seven cells of the root parenchyma, which begin to enlarge and become multinucleate, forming giant cells and galls (Abad et al. 2009; Jones and Goto 2011; Perry and Moens

Corresponding author: M. L. C. Vieira; E-mail address: mlcvieir@usp.br

*The $\boldsymbol{e}$-Xtra logo stands for "electronic extra" and indicates that three supplementary tables are published online.

http://dx.doi.org/10.1094/PHYTO-07-15-0160-R

(C) 2016 The American Phytopathological Society
2011). As the nematode feeds, the xylem vessels become disrupted and the roots cannot function normally (Gosling 2005).

Despite its importance to agriculture, selection for improving plant nematode resistance is a complex procedure, particularly in tropical regions because of the large number of races and nematode species occurring in tropical soils, making it difficult to identify resistant plant varieties (Starr et al. 2002). Furthermore, plant resistance to nematodes is usually found in wild taxa and identifying resistance and its introgression into commercial varieties is a timeconsuming and expensive process (Caromel and Gebhardt 2011). Some common bean genotypes have been considered resistant to $M$. incognita, and partial resistance is apparently prevalent (Ferreira et al. 2010; Saka 1990; Santos et al. 2012). However, this resistance is race-specific and strongly influenced by the environment, especially high temperature (Agrios 2005; Mullin et al. 1991; Sydenham et al. 1997). Consequently, further evaluation of resistance does not result in confirmation, especially under dissimilar environmental conditions involving different nematode populations.

Several studies have led to the identification of parasitism genes and effectors that modulate plant cell functions and promote infection (reviewed by Quentin et al. 2013), and revealed that the establishment of feeding cells is the result of extensive changes in gene expression in the infected root cells. Over the last two decades a number of studies have been done to clarify the molecular mechanisms involved in plant response to sedentary nematode infection (reviewed in Kyndt et al. 2013; Li et al. 2015). Special efforts were made to identify plant genes expressed upon nematode infection using, for instance, microarray (Barcala et al. 2010; Jammes et al. 2005) and RNA-seq assays (Beneventi et al. 2013; Ji et al. 2013; Xu et al. 2012). 
Although some aspects of the plant-nematode interaction have been elucidated in well-studied species, many questions remain to be answered about host gene expression changes that result in a compatible reaction, mainly with regard to tropical crops. In particular, the transcriptome of $P$. vulgaris expressed in response to $M$. incognita attack remains unidentified, especially when the RNA-seq technique is used. This study presents valuable information about common bean genes involved in responding to this pathogen infection, comparing the global transcriptome from infected roots with the transcriptome from uninfected plant roots.

\section{MATERIALS AND METHODS}

Plant material and nematode inoculation. The common bean cultivar IPR Saracura, released by the Instituto Agronômico do Paraná, Brazil (IAPAR 2004), was used in this study. Seeds were sown in moistened Germitest (CIAL, Paulínia, Brazil) paper rolls and kept for 3 days in the dark at $28^{\circ} \mathrm{C}$ in a Dual Program Illuminated Incubator 818 (Precision Scientific, Chicago, IL). After germination, plantlets were transferred to plastic grow bags (1 liter) containing an autoclaved $\left(120^{\circ} \mathrm{C}, 2 \mathrm{~h}\right)$ soil mixture $(73 \%$ sand, $20 \%$ clay, and $7 \%$ silt). Four days later, the plantlets were inoculated based on the following protocol.

First, a nematode population of $M$. incognita (race 3) collected from a cotton field in western-central Brazil $\left(15^{\circ} 33^{\prime} 60^{\prime \prime} \mathrm{S} 55^{\circ} 10^{\prime} 08^{\prime \prime} \mathrm{W}\right)$ was used to isolate nematodes from plant roots using the Coolen and D'Herde (1972) method. Then successive multiplication cycles were performed in order to obtain an inoculum bank, alternately kept in susceptible cotton (Gossypium hirsutum 'Fibermax 966', Bayer CropSciences, Lubbock, TX), carrot (Daucus carota 'Brasília RL', Sakata, Bragança Paulista, Brazil), and tomato (Solanum lycopersicum 'Santa Clara VF5600', Sakata) plants. These plants were kept in the greenhouse, in pots ( 2 liter) containing the same autoclaved soil mixture, to which an aqueous suspension containing eggs and $\mathbf{J}_{2}$ nematodes was added.

Subsequently, roots from six tomato plants were processed for $1 \mathrm{~min}$ in a blender containing $1 \%$ (vol/vol) commercial $\mathrm{NaOCl}$ solution. The solution was filtered and the processed roots collected from the 60/500 mesh sieves, and rinsed in tap water. Next, a modified Baermann technique was used for nematode $\left(\mathrm{J}_{2}\right)$ extraction (Hooper 1986). The inoculum was quantified under light microscopy, using a counting slide. The number of nematodes was counted twice to calculate an average expressed per a given volume $\left(\mathrm{J}_{2} \mathrm{ml}^{-1}\right)$. Each plant was inoculated with an aqueous suspension containing $1,000 \mathrm{~J}_{2}$, distributed in two holes (20 and $40 \mathrm{~mm}$ deep) opened in soil ( $7 \mathrm{~mm}$ in diameter). After inoculation, they were covered with vermiculite to prevent the holes drying up.

Nematode development in common bean roots. A histological analysis was conducted with the aim of identifying appropriate time points for studying plant gene expression in response to nematode infection. $M$. incognita development in 'IPR Saracura' roots was evaluated at eight time points: 1, 2, 4, 10, 16, 22, 30 , and 36 days after inoculation (DAI). The experimental design was entirely randomized with four replicates per time point, giving a total of 32 plants (or plots) kept in the greenhouse. Plant roots were collected, stained with acid fuchsin (Byrd et al. 1983), examined under optical microscopy (Olympus BX50, Olympus, Hamburg, Germany), and photographed with an OPTIKAM B3 digital camera (Optika SRL, Bergamo, Italy).

Transcriptome assay and estimation of nematode reproduction factor. Based on the histological analysis results, two time points were chosen to perform the transcriptome assay, 4 and 10 DAI. This experiment was conducted in anti-aphid cage in an entirely randomized greenhouse arrangement and with three biological replicates of each treatment (inoculated and control), giving a total of 12 plants. The individual plants were harvested and the roots were washed in tap water and immersed in a $20 \%$ (vol/vol) commercial $\mathrm{NaOCl}$ solution $(4 \mathrm{~min}$ ). The $\mathrm{NaOCl}$ residue was removed by surface washing and immersing the roots in water (15 min), leaving the plants intact to prevent tissue oxidation and RNA degradation. Finally, the roots were longitudinally divided into two portions. One half was frozen in liquid nitrogen for total RNA extraction and the other half was stained with acid fuchsin to verify the presence of nematodes in all biological replicates.

In order to estimate the nematode reproduction factor (RF), an additional experiment was carried out concomitantly with the one described above and under the same conditions. RF was estimated according to Oostenbrink (1966) at 68 DAI using a set of 10 common bean plants. Nematodes were extracted from all roots as described in Coolen and D'Herde (1972), observed under an optical microscope, and quantified using a counting slide. The number of nematodes was counted twice to calculate an average expressed per a given volume $\left(\mathrm{J}_{2} \mathrm{ml}^{-1}\right)$. Finally, the RF was calculated as follows: $\mathrm{RF}=$ final population/initial population. Another set of 10 plants was used to verify absence of contamination.

RNA extraction, library construction, and sequence analyses. Approximately $200 \mathrm{mg}$ of frozen root tissue was macerated in liquid nitrogen and used for total RNA extraction using TRIzol reagent (Invitrogen, Carlsbad, CA) according to manufacturer's instructions. The quality of the total RNA was verified using the Agilent 2100 Bioanalyzer (Agilent Technologies, Palo Alto, CA) and the Agilent RNA 6000 nano assay protocol, considering the RNA integrity number (RIN). Only RNA samples that presented suitable quality scores (RIN > 8) were used for the RNA library preparation.

Subsequently, libraries were constructed following the Illumina manufacturer's protocol in the "TruSeq RNA sample preparation v2 low throughput (LT)" kit; a unique barcode was assigned to each biological sample (12). Paired-end sequencing was performed on the Illumina platform (MiSeq), generating 101-bp long reads. Six samples per lane of the flow cell were used. Sequencing data were examined based on the transcriptome analysis algorithms implemented in CLC Genomics Workbench V7.0.1 (CLC Bio, Aarhus, Denmark). Reads were analyzed by QC reports and low quality bases were removed using Quality Trimmer with the following settings: (i) quality score $=0.01$; (ii) maximum number of ambiguous bases $=2$; and (iii) minimum read length $=50 \mathrm{bp}$. To ensure that only highquality sequence regions were selected, five bases from the $5^{\prime}$ ends and one base from the $3^{\prime}$ ends were eliminated from all reads.

Next, the transcripts from the 4 DAI and 10 DAI plant materials were recovered from the total number of reads by mapping to the complete genome of both P. vulgaris (Schmutz et al. 2014) and $M$. incognita (Abad et al. 2008) using the RNA-Seq analysis tool implemented in CLC Genomic Workbench. In particular, our reference was the Pvulgaris_218 genome sequence of the Andean common bean genotype G19833, available on the Phytozome comparative platform (ftp://ftp.jgi-psf.org/pub/compgen/phytozome/ v9.0/Pvulgaris). For $M$. incognita, our reference was m_incognita. PRJEA28837.WS241, available in WormBase (http://www.wormbase. org/species/m_incognita\#10-10). The settings were as follows: alignment penalties of mismatch: 2 , insertion: 3 , deletion: 3 , minimal fraction of length: 0.90 , minimum similarity fraction: 0.95 , maximum number of hits per read: 10 , and automatic paired distance estimation. Next, the number of host transcripts mapped per kilobase of exon model per million mapped reads (RPKM) was computed.

Using the Set Up Experiment tool, we defined the groups to be compared, i.e., inoculated transcripts and respective controls captured at both time points (4 and $10 \mathrm{DAI}$ ). Then, we performed the empirical analysis of differential gene expression based on the exact testing procedure (Robinson and Smyth 2008), which takes a negative binomial distribution in order to search for and generate a list of differentially expressed genes.

Absolute fold-change (FC) cutoffs of $\geq 2$ and $P$ values adjusted for multiple testing using a false discovery rate (FDR) (Benjamini and Hochberg 1995) correction for a given significance level of $\alpha \leq 0.05$ were used to check the significance of differential gene expression. 
Finally, the significant expression values were converted at $\log _{2} \mathrm{FC}$ scale using the R software (R Core Team 2012).

Quantitative gene expression analysis by real-time polymerase chain reaction (PCR). A subset of 15 differentially expressed genes was selected to perform a relative quantification by real-time PCR, according to Munhoz et al. (2015). Briefly, primers were manually designed and primer quality verified based on Gene Runner parameters (http://www.generunner.net/) as follows: 100 to $200 \mathrm{bp}$ as the ideal amplicon size range; primer length from 18 to 22 bases with a 40 to $60 \%$ GC content, absence of secondary structures (such as dimers and hairpins), and melting temperature from 58 to $62^{\circ} \mathrm{C}$ (Table 1 ).

Initially, the total RNA was treated with DNAse (Promega, Madison, WI) and ss-cDNA was synthetized from $1 \mu \mathrm{g}$ of RNA. The reaction mixture contained $1 \times$ of M-MLV reverse transcription (RT) buffer, $0.6 \mathrm{mM}$ of each dNTP, $25 \mathrm{U}$ of RNasin (Promega), $200 \mathrm{U}$ of M-MLV RT (Promega), $0.25 \mu \mathrm{M}$ of primer CDS (5'AAG CAG TGG TAT CAA CGC AGA GTA CTT TTT TTT TTT TTT TTT TTT TTT TTT TTT TTN V3'). DEPC-treated water $(0.01 \%)$ was added to a final volume of $25 \mu \mathrm{l}$, and the reaction was incubated at $42^{\circ} \mathrm{C}$ for $1 \mathrm{~h}$.

Subsequently, the 12 biological samples (three inoculated and three control plants for each time point) were amplified by quantitative PCR (qPCR), using technical triplicates. Amplifications were performed on a StepOne Real-Time PCR System (ABI, CA). The reaction mix contained $2.5 \mu \mathrm{l}$ of ss-cDNA $20 \times$ diluted, $5.1 \mu \mathrm{l}$ of GoTaq qPCR Master mix (Promega), $0.3 \mu \mathrm{M}$ of each primer, and water was added to a final volume of $10 \mu \mathrm{l}$. Cycling conditions were as follows: $95^{\circ} \mathrm{C}$ for $5 \mathrm{~min} ; 40$ cycles of $95^{\circ} \mathrm{C}$ for $5 \mathrm{~s}$ and $60^{\circ} \mathrm{C}$ for $1 \mathrm{~min}$. Reaction specificity was confirmed by obtaining the dissociation curve for every reaction. Four common bean genes transcribed at a constant level across replicates, encoding WUSCHEL related homeobox 4 (WOX4), transcription elongation factor (TEF), ferredoxin ( $\mathrm{Fd}$ ), and $26 \mathrm{~S}$ protease regulatory subunit $(\mathrm{P} 26 \mathrm{~S})$ were used as endogenous reference genes to normalize expression signals (Table 1). A Cq value was obtained for each reaction, which is the fractional cycle number at which fluorescence increases above the threshold. PCR efficiencies per sample and the corresponding $\mathrm{Cq}$ values were obtained using the LinReg PCR program (Ramakers et al. 2003). Only samples with efficiency values higher than $95 \%$ were considered for expression analysis. Relative changes in gene expression ratios were calculated based on the $2^{-\Delta \Delta C t}$ method (Livak and Schmittgen 2001). Control samples were used as calibrators. The $t$ test was used to estimate significant changes in relative expression levels $(P<0.05)$. The Pearson's correlation coefficient was used as a measure of the expression difference between the RNA-seq and qPCR data, using the R software (R Core Team 2012).

Functional annotation and enrichment analysis. Functional annotation of the set of unigenes was performed using Blast2GO v.2.7.1 (Conesa et al. 2005) in accordance with BLASTx results, taking an e-value cutoff of $1 \times 10^{-6}$, followed by mapping and annotation steps using the default parameters of Blast2GO.

Then, the following approaches were used on the set of differentially expressed unigenes: AgriGO tool, which supports special focus on agricultural species, was used to perform a singular enrichment analysis (SEA) (FDR correction and Fisher's exact test $\leq 0.1$ ) using the Phaseolus vulgaris v1.0 data set as the reference. Significant GO terms related to the biological process were summarized and visualized in the TreeMap view supported in REVIGO (Supek et al. 2011), a computational approach that summarizes long GO lists by reducing functional redundancies. In

TABLE 1. Sequence of the forward (F) and reverse (R) primers designed from the common bean transcripts detected by RNA-seq approach and used in assays for quantifying gene expression by quantitative polymerase chain reaction (qPCR)

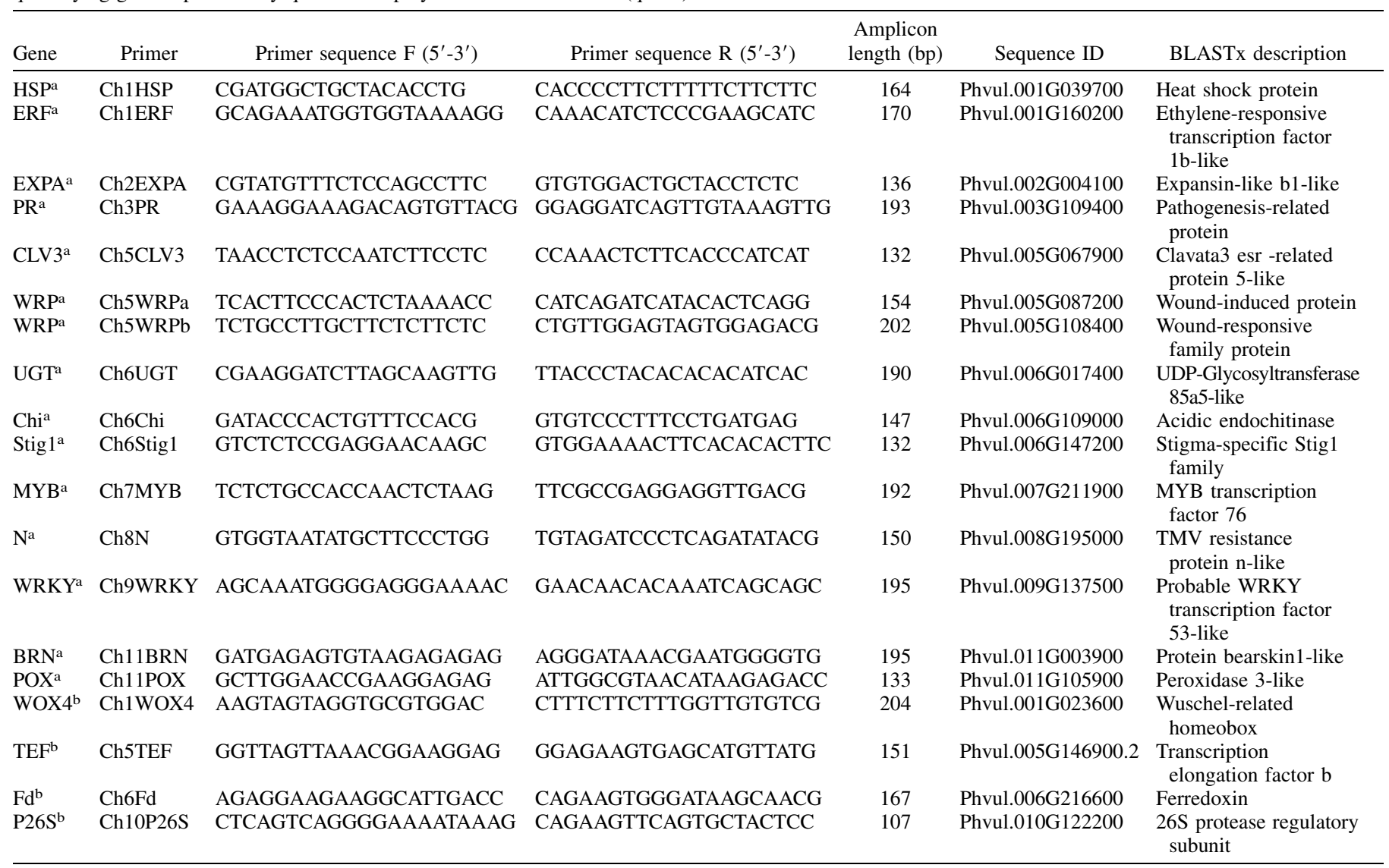

a Differentially expressed genes detected by RNA-seq approach.

b Endogenous reference genes used to normalize relative gene expression quantification. 
addition, BLASTx was used to align the unigene sequences against all plant databases embedded in the Mercator web tool (Lohse et al. 2014). Each transcript was assigned to a single BIN (the multiple BIN assignment was not selected) and a BLAST cutoff of 80 was chosen. Mapping files generated by Mercator were used to assign the unigene sequences to functional pathways in MapMan v.3.5.1R2 (Thimm et al. 2004; Usadel et al. 2005).

Finally, the differential expressed unigenes common to both time points were graphically represented by a hierarchically clustered heatmap. The $\log _{2}$ FC values were clustered using the McQuitty hierarchical clustering method (McQuitty 1966) implemented on the hclust package and the heatmap was produced by running the heatmap.2 function in the gplots package (Warnes et al. 2014), both in the R software suite (R Core Team 2012).

\section{RESULTS}

Nematode development in common bean roots. In the trial used to determine suitable time points for RNA isolation, an absence of nematodes was observed on the first and second day after inoculation. Mobile $\mathrm{J}_{2}$ were found to have invaded root tissues at 4 DAI (Fig. 1A), and the establishment of feeding sites at 10 DAI
(Fig. 1B). From 10 to 30 DAI, the sedentary stage development (Fig. $1 \mathrm{~B}$ to $\mathrm{E}$ ) and the subsequent onset of a new infection cycle was seen at 36 DAI (Fig. 1F). We therefore chose to analyze the host transcriptional responses to $M$. incognita infection at two time points: 4 DAI and 10 DAI.

Transcriptome assay and estimation of nematode reproduction factor. In the trial used for library construction, the presence of nematodes was confirmed in all inoculated plant roots, and absence of nematodes in control plant roots. The average nematode reproduction factor was 22.6 , confirming the compatibility between 'IPR Saracura' and $M$. incognita.

Library features. The Illumina platform produced a total of 595.08 million reads of $101 \mathrm{bp}$ in length, including 288.81 million (48.5\%) from 4 DAI samples and 306.27 million (51.5\%) from 10 DAI samples (Table 2). Raw sequence data are available at NCBI BioProject database (http://www.ncbi.nlm.nih.gov/bioproject) under accession number PRJNA288189.

After trimming, the percentage of high-quality sequences in each treatment was 73\% (inoculated roots) and $80 \%$ (controls). Approximately 327 million (327/595, 55.0\%) RNA-seq reads were mapped to the genome of $P$. vulgaris as reference, and 27,195 unigenes were identified. In regard to $M$. incognita, $\leq 0.07 \%$ reads

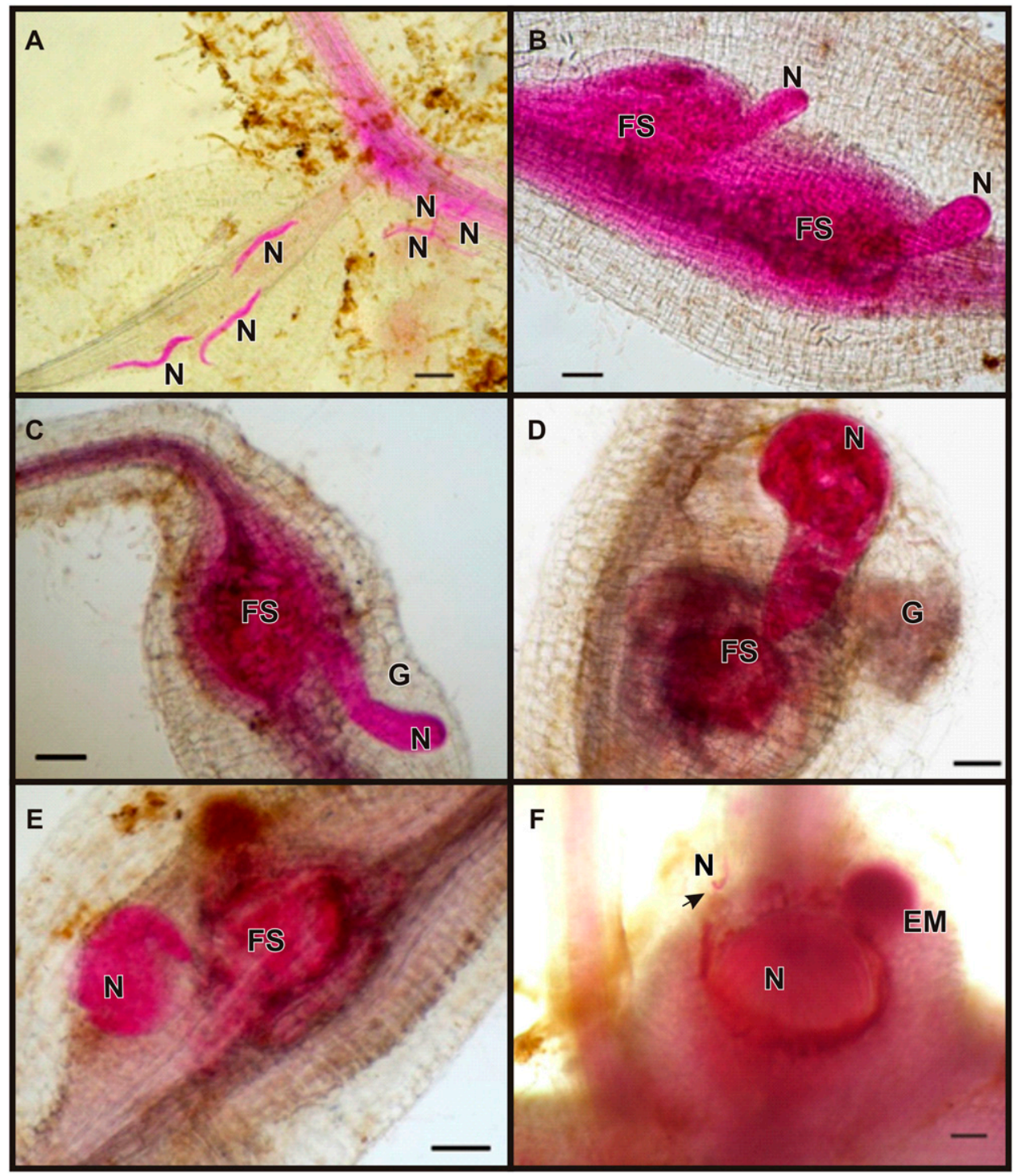

Fig. 1. Photomicrographs of the developmental stages of Meloidogyne incognita within the 'Saracura' common bean roots. A, Infecting juveniles ( $\left.\mathrm{J}_{2}\right)$ migrating to vascular cylinder (4 days after inoculation [DAI]); B, sausage-shaped juveniles initiating feeding sites (FS) (10 DAI); C, sausage-shaped juvenile feeding itself and galling $(\mathrm{G})$ occurrence as a response to parasitism (16 DAI); D, young female (22 DAI); E, adult female (30 DAI); and F, adult female producing egg masses (EM) and the onset of a new infection cycle (arrow indicates a $\mathbf{J}_{2}$ ) (36 DAI). Bars $=100 \mu \mathrm{m}$. N, nematode. 
(Table 2) were mapped to its reference genome (2,929 reads from 4 DAI and 32,691 from 10 DAI samples). For this reason, only the common bean transcriptome was subsequently taken into account.

We were able to identify 797 differentially expressed genes, 508 at $4 \mathrm{DAI}, 210$ at $10 \mathrm{DAI}$, and 79 at both time points (based on $\log _{2} \mathrm{FC}$ $\geq 1$ ) (Supplementary Table S1). As shown in Figure 1, the first time point correlates with nematode penetration and the second corresponds to giant cell development. Compared with the control, in the early period of interaction, 293 genes were found to be upregulated and 294 down-regulated. The most up-regulated was a bearskinl-like (BRN) gene (Phvul.011G003900), identified in Arabidopsis as a gene related to root cap maturation (Bennett et al. 2010). On the other hand, the most down-regulated gene was the stigma-specific Stigl (Phvul.006G147200), whose function is unknown. As far as we know, this is the first time that bearskin1like and Stigl have been identified among the genes involved in plant response to nematode infection. In the late period of the interaction, 117 genes were found up-regulated and 172 downregulated. At this time point (10 DAI), genes related to the defense response were the ones with the highest FC: a wound-responsive gene (Phvul.005G108400) was found highly up-regulated, and a peroxidase gene highly down-regulated (Phvul.011G105900).

The relative gene expression data using real-time qPCR was consistent with all the above-mentioned results; as previously reported for other plant-pathogen interactions (Camilios-Neto et al. 2014; Gao et al. 2013), our qPCR data showed a good correlation with the RNA-seq data. The Pearson's correlation coefficients between qPCR and RNA-seq data were 0.88 and $0.96(P<0.0001)$ for 4 and 10 DAI samples, respectively. Interestingly, the qPCR was more sensitive in detecting the expression level of these genes (Fig. 2). For instance, for the BRN gene, the FC values $(P$ value $\leq 0.05)$ for RNA-seq and qPCR were 12.87 and 22.44, respectively.

Functional annotation. The BLASTx results showed that 27,043 unigenes (99.4\%) were similar to plant proteins. As expected, the vast majority of the top-hits made by our sequences were to $P$. vulgaris $(91.4 \%)$ and to other related plant species, including Glycine max (3.4\%). Altogether 14,099 unigenes were assigned to ontological terms using the Blast $2 \mathrm{GO}$ tool. Restricting the analysis to level 2, 43 GO terms were annotated: within the category biological process, the most frequent GO terms were metabolic process and cellular process; in the molecular function category, the most frequent terms were catalytic activity and binding; and in the cellular component category, cell, organelle, and membrane were the most abundant terms (Fig. 3).

The singular enrichment analysis results showed that 23 functional categories were relevant to the $P$. vulgaris $-M$. incognita interaction, including five common to both time points. At 4 DAI, we identified 14 functional categories, belonging to eight clusters according to REVIGO (Fig. 4A). The most gene-rich categories were metabolism (116 up-regulated and 79 down-regulated genes) and oxidationreduction process (56 up-regulated and 15 down-regulated genes). One of the clusters exclusive to 4 DAI (shown in blue, Fig. 4A) and composed of four categories is related to cell wall metabolism, reflecting the phase of nematode penetration. At $10 \mathrm{DAI}$, we also identified 14 functional categories, but they were grouped into five clusters (Fig. 4B). The oxidation-reduction process was the most gene-enriched category ( 7 up-regulated and 35 down-regulated). Only one of the clusters, composed of seven categories, is exclusive to 10 DAI (shown in purple, Fig. 4B), and is related to DNA conformation change, probably reflecting the phase of host cell endo-reduplication initiated by nematode feeding site establishment (de Almeida Engler and Gheysen 2012).

Based on the results of gene classification into MapMan hierarchical categories (BINs), 797 genes were assigned to 29 BINs, including 199 genes classified as unknown proteins.

At 4 DAI, the genes were assigned to 26 BINs (Fig. 5A). Five BINs contained only genes that were up-regulated (fermentation, major carbohydrates, glycolysis, metal handling, and redox) and seven BINs contained only down-regulated genes (photosynthesis, minor carbohydrates, OPP cycle, TCA/organic acid transformations, cofactor and vitamin metabolism, biodegradation of xenobiotics and cell). Focusing on plant defense, $22 \%$ of the genes (175/797) were assigned to $10 \mathrm{BINs}$, chiefly hormone signaling (27/175), transcription factors (21/175), cell wall (29/175), and oxidative stress (11/175) (Fig. 6, Supplementary Table S2). In regard to hormone signaling, we observed a predominance of genes related to ethylene (ET) (five up- and eight down-regulated) and jasmonic acid (JA) biosynthesis (six up- and two down-regulated). Four auxin-related genes were differentially expressed, three of them (Phvul.006G101300, Phvul.008G001500, and Phvul.003G139600) were up- and one (Phvul.006G116100) was down-regulated. Moreover, a brassinosteroid-related gene, cytochrome P450 (Phvul. 010G053100), was found to be up-regulated. Of the transcription factors, 17 (10 MYB, 5 WRKY, and 2 AP2/EREBP) were down-regulated and four (1 MYB, 2 WRKY, and 1 AP2/EREBP) up-regulated. In regard to cell wall, a cellulose synthase (Phvul. 005G001000), an alpha-1,4-glucan-protein synthase (Phvul. 004G041600), four expansins (Phvul.001G003700, Phvul.009G019000, Phvul.007G207600, and Phvul.002G083600), and a xyloglucan endotransglycosylase-related protein (Phvul.011G085200) were upregulated. Conversely, a cellulose synthase-like (Phvul.006G058700), an expansin (Phvul.008G232200), an expansin-like B1 precursor (Phvul.002G004100), and four xyloglucan endotransglycosylase/ hydrolases (Phvul.003G147500, Phvul.009G233200, Phvul.003G147400, and Phvul.003G052400) were down-regulated. In addition, a glycosil hydrolase (Phvul.008G081200) and pectin lyase-like (Phvul. 008G123000) were induced and a rhamnogalacturonate lyase (Phvul.003G287200) and a polygalacturonase precursor (Phvul. 005G022500) were repressed. Six genes encoding pectinesterases were differentially expressed, four of them (Phvul.007G206300, Phvul.010G079900, Phvul.011G188900, and Phvul.002G270900) were up-regulated and two (Phvul.003G015600 and Phvul.005G011900) were down-regulated. Finally, concerning oxidative stress, we identified eight genes encoding peroxidases (seven up- and one down-regulated), as well as a thioredoxin-like (Phvul.009G186300) up-regulated and a glutathione-S-transferase gene (Phvul.006G079600) down-regulated. It is interesting to note that at this time point, there were transcriptional changes in defense- and cell wall-related pathways, which could lead to cell wall alterations, probably activated by the host response. Furthermore, an up-regulated gene, TIR-NBSLRR (Phvul.008G195000), was recognized and is similar to the R genes that provide resistance to Tobacco mosaic virus (Whitham et al. 1994).

TABLE 2. Total and average number of reads captured in the early (4 days after inoculation [DAI]) and late (10 DAI) time points and number of reads mapped to the respective reference genomes ${ }^{\mathrm{a}}$

\begin{tabular}{|c|c|c|c|c|c|c|c|}
\hline & & \multirow[b]{2}{*}{ Total number of reads } & \multirow[b]{2}{*}{ Average number of reads } & \multicolumn{2}{|c|}{ Phaseolus vulgaris } & \multicolumn{2}{|c|}{ Meloidogyne incognita } \\
\hline & & & & Mapped reads & $\%$ & Mapped reads & $\%$ \\
\hline \multirow[t]{2}{*}{ Control } & $4 \mathrm{DAI}$ & $157,260,977$ & $52,420,326(9,633,585)$ & $87,020,000$ & 55.33 & 91 & 0.00 \\
\hline & 10 DAI & $168,804,531$ & $56,268,177(7,973,533)$ & $80,190,000$ & 47.50 & 123 & 0.00 \\
\hline \multirow[t]{2}{*}{ Inoculated } & $4 \mathrm{DAI}$ & $131,562,681$ & $43,854,227(8,264,915)$ & $79,160,000$ & 60.18 & 2,482 & 0.00 \\
\hline & 10 DAI & $137,476,872$ & $45,825,624(15,072,813)$ & $81,130,000$ & 59.02 & 98,074 & 0.07 \\
\hline
\end{tabular}

a Data refer to three biological replicates with standard deviations shown in parenthesis. 

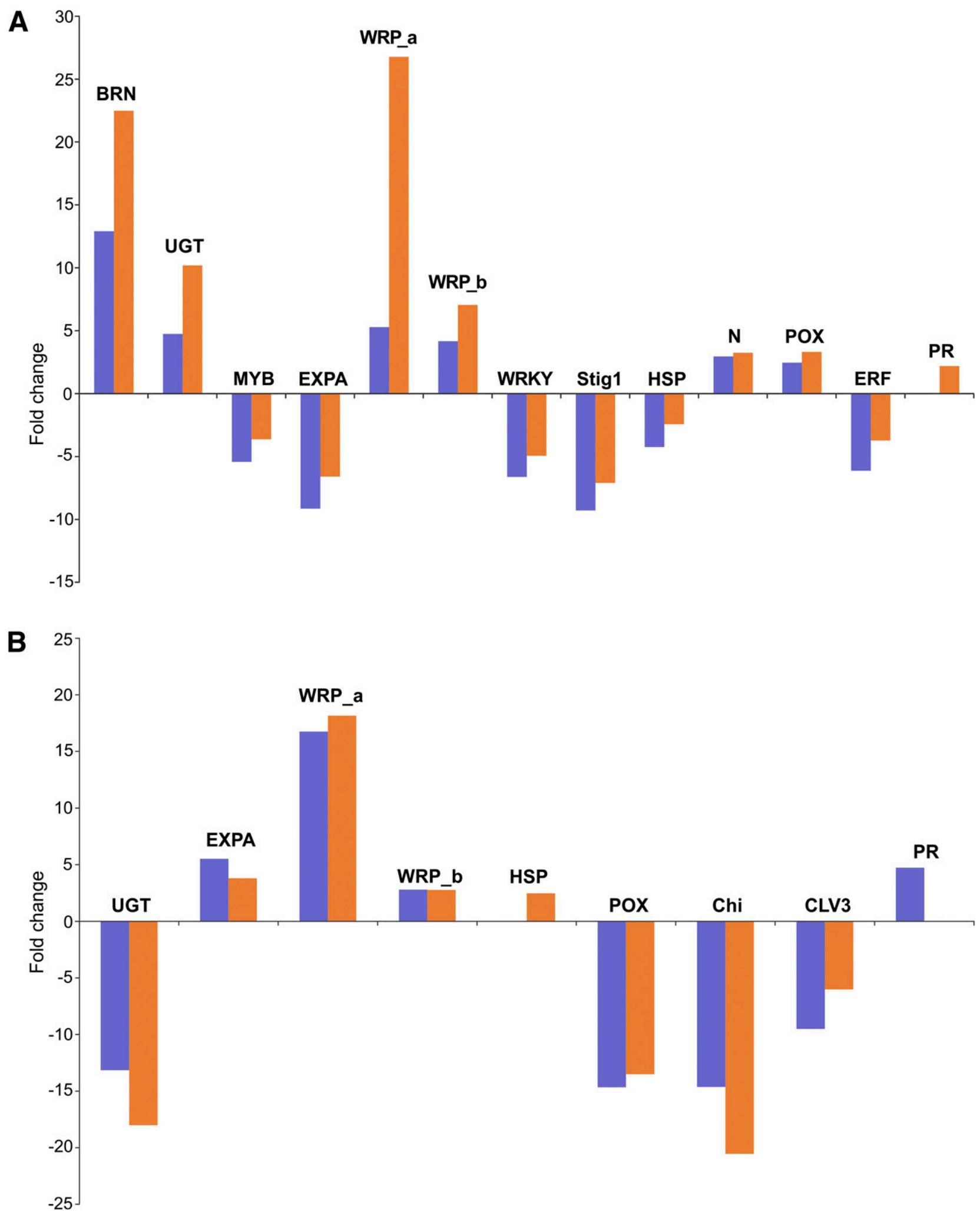

Fig. 2. Relative expression levels of 15 common bean genes in response to nematode infection at $\mathbf{A}, 4$ days after inoculation (DAI) and $\mathbf{B}, 10 \mathrm{DAI}$ obtained from RNA-seq (dark gray/blue bars) and quantitative polymerase chain reaction (qPCR) (light gray/orange bars) data. At each time point, only the significantly changed genes are shown. Genes coding for Wuschel-related homeobox, transcription elongation factor, ferredoxin, and 26S protease regulatory subunit were used to normalize the expression values for each target gene. BRN, Bearskin1; UGT, UDP-glycosyltransferase; MYB, MYB transcription factor; EXPA, Expansin; WRP_a and WRP_b, wound-responsive proteins; WRKY, WRKY transcription factor; Stig1, stigma-specific gene family; HSP, heat shock protein; N, Tobacco mosaic virus resistance protein; POX, peroxidase; ERF, ethylene-responsive transcription factor; PR, pathogenesis-related protein; Chi, acidic endochitinase; and CLV3, Clavata3 esr-related protein. Note the consistency between RNA-seq and qPCR data. 
At the time that corresponds to giant cell development (10 DAI), the genes were assigned to 22 BINs (Fig. 5B). Six BINs contained only up-regulated genes (signaling, nucleotide metabolism, cell, TCA/organic acid transformations, glycolysis, and minor carbohydrates) and two BINs down-regulated genes (biodegradation of xenobiotics and nitrogen assimilation). Two BINs (nucleotide metabolism and DNA) were found to be exclusive to this time point, reflecting host cell endo-reduplication. Focusing on plant defense, $11 \%(92 / 797)$ of the genes were assigned to the abovementioned BINs, except beta glucanase (Fig. 6, Supplementary Table S3). In regard to hormone signaling, a predominance of downregulated genes was observed (11/12). Expression levels were reduced for all genes related to ET biosynthesis and signaling, i.e., aminocyclopropane-1-carboxylic acid (ACC) oxidases (Phvul. 007G135600, Phvul.008G213900, Phvul.008G213800, and Phvul. 002G326600) and ethylene responsive factors (Phvul.001G160100 and Phvul.008G046400). Moreover, the genes for JA biosynthesis, three lipoxygenases (Phvul.010G135600, Phvul.010G135800, and Phvul.005G156800) and one allene oxide cyclase (Phvul.003G111500) were down-regulated. A brassinosteroid-related gene (Phvul.011G011800) was up-regulated and one abscisic acid-related gene (Phvul.001G193400) was down-regulated. Expression of WRKY transcription factors (Phvul.009G087400 and Phvul.002G160100) was induced and an MYB transcription factor (Phvul.004G116500) was downregulated. In regard to the cell wall, an expansin-like B1 precursor (Phvul.002G004100), a xyloglucan endotransglycosylase/hydrolase (Phvul.003G147700), a rhamnogalacturonate lyase (Phvul.003G287200), a polygalacturonase precursor (Phvul.005G022500), and a pectin lyase-like (Phvul.003G015600) were up-regulated and two expansins (Phvul.006G077200 and Phvul.008G120700), a pectin methylesterase (Phvul.002G048700) and a polygalacturonase (Phvul. 003G052000) were down-regulated. Related to oxidative stress, we found two up-regulated genes, a glutathione-synthase (Phvul. 006G094500) and a glutathione-S-transferase gene (Phvul. 006G079600) but also detected a reduction in the expression levels of five peroxidases, a peroxiredoxin (Phvul.001G186000), L-ascorbate oxidase precursor (Phvul.006G011700), and GDPmannose 3,5-epimerase (Phvul.006G101600). Overall, a reduction in gene expression levels of certain categories was observed (Fig. 6 ), namely hormone signaling, oxidative stress, biotic stress, and secondary metabolism.

In regard to the set of genes differentially expressed in both time points (79), 15 showed continuous differential expression (Fig. 7), 14 were up-regulated and one of unknown function (Phvul.009G132200) was down-regulated. Most of the up-regulated genes (6/14) were wounding-responsive genes, reflecting host responses to nematode penetration. The remaining genes (64) showed an opposite expression pattern depending on the time point of the interaction. This applies in particular to genes assigned to the cell wall degradation and modification (down-regulated at 4 DAI, but up-regulated at $10 \mathrm{DAI}$ ) and hormone metabolism (up-regulated at 4 DAI, but down-regulated at $10 \mathrm{DAI})$.

\section{DISCUSSION}

The dynamic of the compatible interaction between $P$. vulgaris and $M$. incognita is illustrated in Figure 7 using gene expression profiles. In particular, modulated expression was noted for wounding-responsive genes that were induced at both time points, and genes involved in the hormonal signaling pathway that were induced at nematode penetration and movement into root cells (4 DAI) but inhibited at the giant cell development step (10 DAI). Furthermore, genes involved in cell wall degradations were induced at $10 \mathrm{DAI}$. All this evidence indicates that the pathogen was efficient at subverting the plant's defense mechanisms.

Modifications in plant cell structure and root development result in the generation of nematode feeding cells (giant cells), possibly as a result of an imbalance of hormones, including auxins (Gheysen and Mitchum 2011; Gutierrez et al. 2009; Saini et al. 2013). We detected overexpression of auxin-related genes at the early stage of parasitism (4 DAI) but not at 10 DAI. Note that the first $\mathrm{J}_{2} \mathrm{~s}$ appeared in root tissues at 3 DAI (data not shown), thus our RNA-seq library contains transcripts accumulated over a period of $24 \mathrm{~h}$. Conversely, Hutangura et al. (1999) reported an accumulation and transportation of auxin at the beginning of gall formation during the first hours of the interaction between Trifolium repens and $M$. javanica. One of the up-regulated transcripts we were able to identify at the nematode penetration stage was the auxin-induced PCNT115, a protein implicated in plant defense (Li et al. 2013; Margaria et al. 2013). A PCNT115 up-regulation was also detected in banana infected with Fusarium oxysporum ( $\mathrm{Li}$ et al. 2013) and its expression increased according to the resistance level of the genotypes under evaluation.

The genes involved in ET biosynthesis and signaling were clearly affected by changes in the expression levels of genes encoding aminocyclopropane-1-carboxylic acid (ACC) synthase, ACC oxidase, and ERF. This hormone production in plant tissues is the result of the conversion of methionine to S-adenosylmethionine to ACC and finally to ET. At the early stage of infection (4 DAI), the repression of ACC synthase transcript affected the first step of ET production, and as time progressed, repression of biosynthesis was confirmed by the down-regulation of all ET-related transcripts (Fig. 6). Changes in the expression of ET-related genes have been frequently detected in plant-pathogen interaction analyses, though there is a lack of consensus on the association between the compatibility of the interaction and the level of expression of these genes (Van Loon et al. 2006). A transient increase in the expression level of ACC synthase and ACC oxidase was observed in both susceptible and resistant tomato plants $12 \mathrm{~h}$ after inoculation (HAI) under M. incognita attack (Mantelin et al. 2013). Herein, ERFs were found to be down-regulated at both time points. These transcription factors act as downstream regulators of ET-responsive genes, suggesting that a decrease in ethylene sensitivity and basal resistance occurred in the pathosystem under analysis. The reduction in sensitivity to this hormone did not affect tomatoes whose resistance to $M$. incognita was conferred by the $M i-1$ gene. However, basal resistance was affected when the interaction was compatible (Mantelin et al. 2013). Furthermore, ERFs are involved in the ET and JA pathway connection, which play an important role in determining whether an interaction is compatible (Grennan 2008; Lorenzo et al. 2003).

Changes in the JA pathway were evidenced by the differential expression of lipoxygenases, 12-oxophytodienoic acid reductases (OPR2 and OPR3-like), and allene oxide cyclase. In the initial stages of the interaction, the injuries caused by nematode infection induced the production of LOX, activating the primary step of JA biosynthesis, which was repressed as time progressed. The same phenomenon was detected for ET biosynthesis. The down-regulation of genes encoding enzymes OPR2 and OPR3-like that act in the second step of JA biosynthesis resulted in the subsequent downregulation of all JA-related genes in the final stages of the interaction (Fig. 6).

We would speculate that ET/JA-dependent defenses against $M$. incognita are active in common bean, but the nematode is able to subvert the defense mechanisms in the course of the interaction. In rice, analyses involving JA mutants, ET-insensitive transgenics and JA-pharmacological inhibition have shown that the JA-pathway is essential to systemically induced defense against $M$. graminicola (Nahar et al. 2011). Despite the evidence that JA activates a succession of signaling pathways resulting in the activation of genes required for diverse functions (reviewed in Liu et al. 2015), including plant defense, intact JA-regulated signaling was identified as required for root-knot nematode (RKN) susceptibility in tomato (Bhattarai et al. 2008). Moreover, lipoxygenase family members have shown distinct functions in Arabidopsis response to M. javanica; LOX3 expression seems to increase susceptibility to this nematode, but LOX4 presents the opposite effect (Ozalvo et al. 2014). ET/JA and salicylic acid (SA) defense pathways were 
activated in tomato infected by RKN in both, compatible and incompatible reaction, though these pathways were more induced in the incompatible one (Bhattarai et al. 2008). Conversely, JA may interact antagonistically with other hormones, such as SA. In this context, the activation of ET/JA pathways we detected at the earlier time point of interaction could have prevented SA pathway activation, leading to a compatible host response to $M$. incognita.

We detected several genes associated with the response to abiotic stress, namely the wounding-responsive genes that reached high levels of expression. At the onset of the interaction, the induction of these genes is the result of root penetration by the nematodes (wounding agents), possibly due to the fact that damage-inducible defenses are controlled by jasmonates that start to accumulate rapidly after a plant tissue is wounded. Consistent with this, Chauvin et al. (2013) sought to identify lipoxygenases that initiate wound-induced jasmonate synthesis within a short timeframe, especially LOX6 in response to long-distance wound signals in A. thaliana.

In turn, the induction of wounding-responsive genes altered the expression of hormone signaling pathway associating genes, as well as the expression of the transcriptional factors MYB and WRKY, genes that produce PR proteins and genes involved in generating reactive oxygen species (ROS) (Cao et al. 2006; Casalongué et al. 2012; Cheong 2002).

The WRKY transcription factors herein identified were previously reported in plant response to nematode infection (Ali et al. 2014; Bhattarai et al. 2008; Ibrahim et al. 2011). Exemplifying, the WRKY33 and WRKY70 were among the transcription factors repressed during root penetration by the nematode (4 DAI). Similarly, WRKY33 was repressed in Arabidopsis, favoring the development of syncytia caused by Heterodera schachtii (Ali et al. 2014). However, the up-regulation of WRKY33 was reported in the tomato response to $\mathrm{RKN}$, in compatible and incompatible reactions (Bhattarai et al. 2008). This transcriptional factor is involved in the synthesis of the phytoalexin camalexin as well as in the positive regulation of ET/JA-related genes (Alves et al. 2014; Seo et al. 2015). Transcription factor WRKY70, also involved in crosstalking between SA and ET/JA pathways (Derksen et al. 2013), has been identified as a key player in tomato resistance to potato aphid (Macrosiphum euphorbiae) and M. javanica, mediated by Mi- 1 gene (Atamian et al. 2012). In contrast, an up-regulation of WRKY70 was observed in soybean 10 weeks after $M$. incognita infection (Ibrahim et al. 2011).

An attempt by the common bean defense system to suppress the $M$. incognita attack was noted in terms of a TIR-NBS-LRR gene overexpression at $4 \mathrm{DAI}$ ( $N$ gene, Fig. 2A). It has been suggested that this gene, homologous to the $N$ gene, plays a role in the hypersensitive response to Tobacco mosaic virus (Whitham et al. 1994) and RKN in pepper (Brito et al. 2007; Kiewnick et al. 2009). We are aware that HSP90 suppression undoes the resistance to Tobacco mosaic virus conferred by the $N$ gene, and to RKN conferred by the Mi-1 gene (Bhattarai et al. 2007; Liu et al. 2004), a cloned $R$ gene for RKN (Milligan et al. 1998; Vos et al. 1998). Changes in HSP expression could explain the loss of resistance in pepper against some RKN species under high temperatures (Brito et al. 2007; Kiewnick et al. 2009).

In regard to HSPs, we found contrasting gene expression responses for the two time points studied. All 14 HSP genes identified in early response were down-regulated, and only HSP70 and HSP83 genes were up-regulated at the later response. Differential expression profiles of HSPs were also detected in other plant-nematode

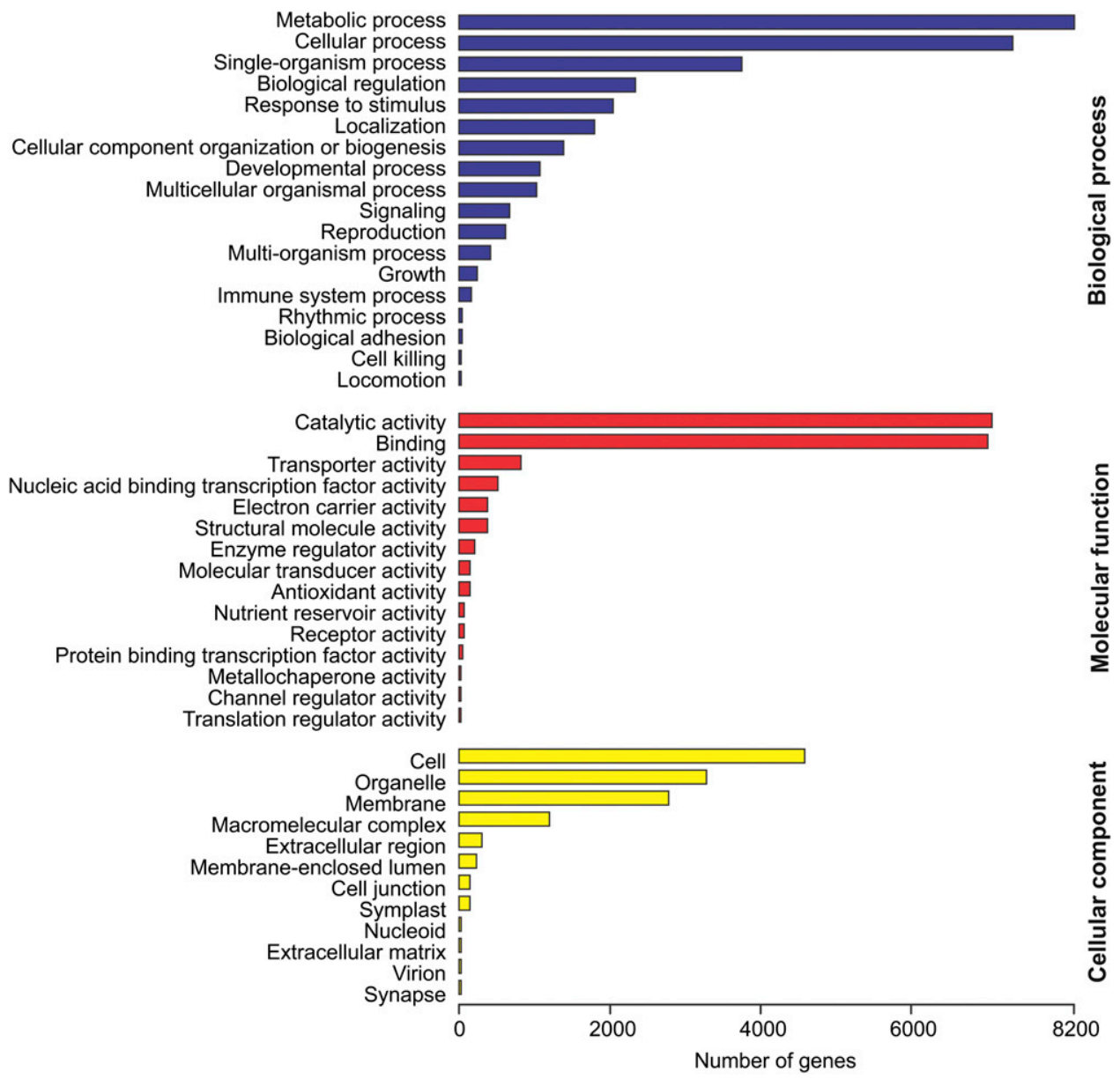

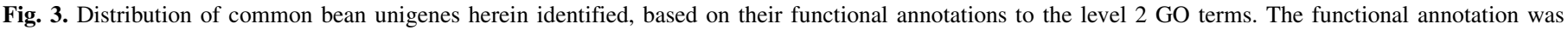
performed using Blast2GO software, in accordance with BLASTx results (e-value $1 \times 10^{-6}$ ). 
interaction studies (Hirao et al. 2012; Szakasits et al. 2009). The HSP70 was up-regulated in incompatible reactions between soybean and $H$. glycines, suggesting its involvement in the cellular function maintenance under stress response (Klink et al. 2007). Furthermore, as already mentioned, HSPs have been identified as components of resistance mechanisms, such as the Hsp90-SGT1-Rar1 complex required for $M$. incognita resistance mediated by the $M i-1$ gene (Bhattarai et al. 2007). Similarly, we can assume that the $N$ genemediated nematode resistance was suppressed in common bean by decreasing the rate of expression of HSPs, as confirmed by qPCR results (Fig. 2A).

Thereafter, a compatible reaction was established as time progressed, also leading to down-regulation of pathogenesis related proteins, e.g., dirigent-like proteins, a protease inhibitor, and an acidic endochitinase, which in particular had its down-regulation confirmed by qPCR results. Note the bar graph relative to Chi gene in Figure 2B.

Several cell wall-related genes were found to have their expression profiles clearly modulated by nematode infection (Fig. 6). This was found for genes involved in the synthesis, degradation, and modification of the cell wall, triggered by nematode penetration at 4 DAI, as well as genes related to cell wall modification that were differentially expressed as a result of giant cell development and maintenance, i.e., expansins (EXP) and xyloglucan endotransglycosylases $(\mathrm{XTH})$ at $10 \mathrm{DAI}$.

Four expansin genes were up-regulated during $\mathrm{J}_{2}$ migration in root tissues and auxin concentration heightening. Both $\mathrm{J}_{2}$ migration and feeding site establishment are dependent on loosening and

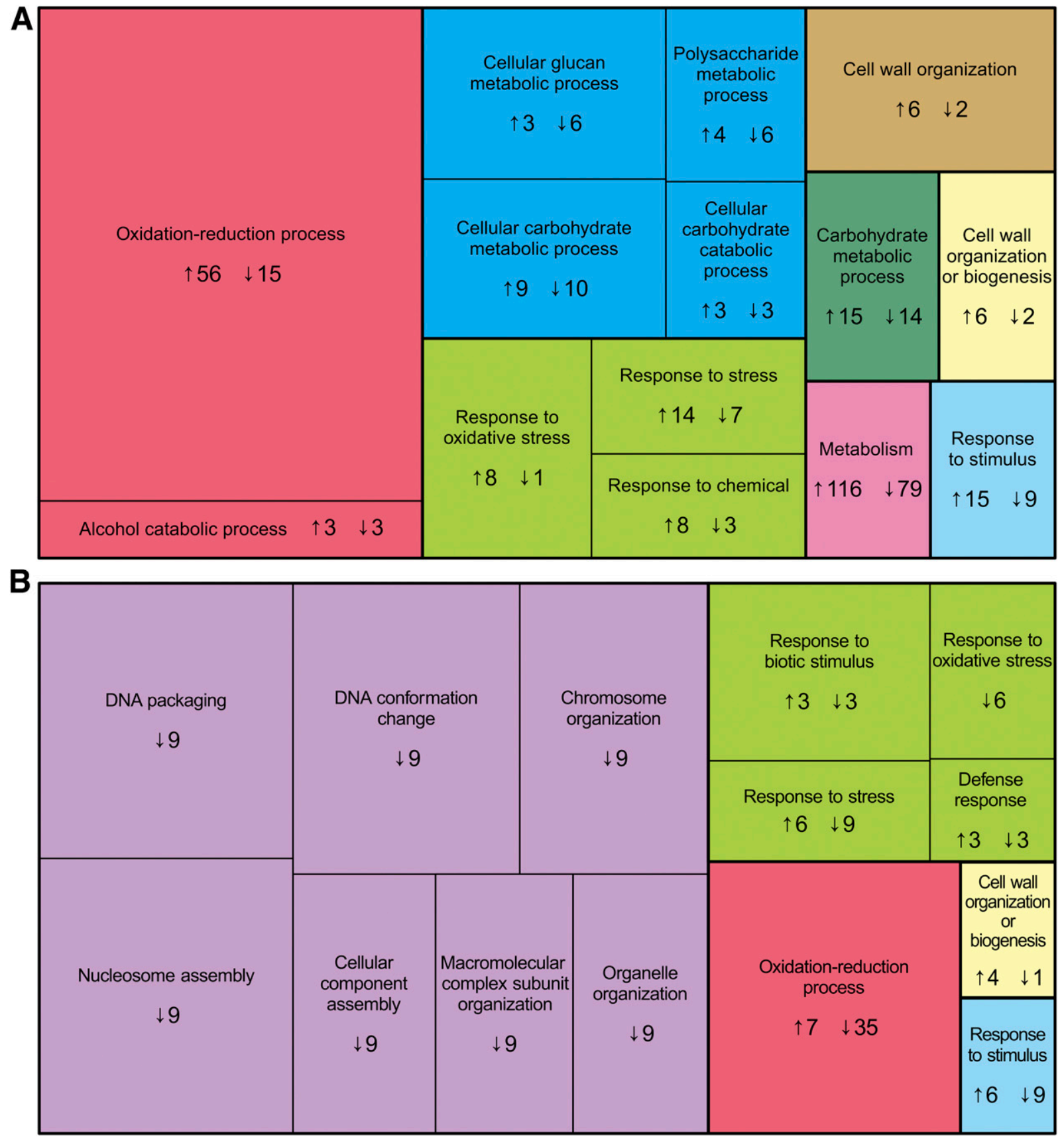

Fig. 4. TreeMap visualization obtained from REVIGO clustering analysis based on semantic similarity measurement (SimRel) of the significant GO terms found in singular enrichment analysis (SEA) performed in AgriGO. SEA was done using the Fisher exact test (false discovery rate $\leq 0.1$ ). Only the biological process category was considered and the list of common bean genes implemented on the AgriGO platform was used as reference. The two sets correspond to two time points at $\mathbf{A}, 4$ days after inoculation (DAI) and $\mathbf{B}, 10$ DAI. Rectangles were adjusted proportionally according to the clustering significances in $\log _{10}(P$ value). The number of genes is indicated in each of the clusters (distinctly colored) and the expression gene trends are shown by arrows pointing up and down. 
degradation of the cell wall. On the other hand, a transcript similar to the Arabidopsis EXPA6 gene was herein continuously repressed. Though the induction of EXPA6 in A. thaliana infected with $M$. javanica was reported previously (Barcala et al. 2010), contrasting expansin expression profiles were identified in the syncitia transcriptome modulated by $H$. schachtii (Wieczorek et al. 2006). XTHs present important roles in plant response to nematode infection acting in cell wall reinforcement once the cell expansion is completed. Several members of the XTH family were identified in this study. XTR6 were down-regulated at 4 DAI as described in soybean tissues infected with $H$. glycines (Puthoff et al. 2007; Tucker et al. 2007), and XTR8 as well as TCH4 were up-regulated at 4 and 10 DAI, respectively. TCH4 was reported to be continuously induced in A. thaliana infected with $H$. schachtii (Szakasits et al. 2009).

In molecular plant-pathogen interactions, ROS act against the pathogen itself or promote plant cell death, leading to a hypersensitive response. To defend themselves against the damage caused by ROS, cells produce antioxidants as peroxidases that act to convert ROS into nonreactive molecules. In our study, a peroxidase downregulated and seven peroxidases up-regulated as well as a thioredoxin overexpressed were detected in the early stages of interaction, probably as a result of ROS production. Thioredoxins were found to be differentially expressed in A. thaliana syncytia modulated by $H$. schachtii, most of them were found to be induced (Szakasits et al. 2009). Interestingly, changes in the expression
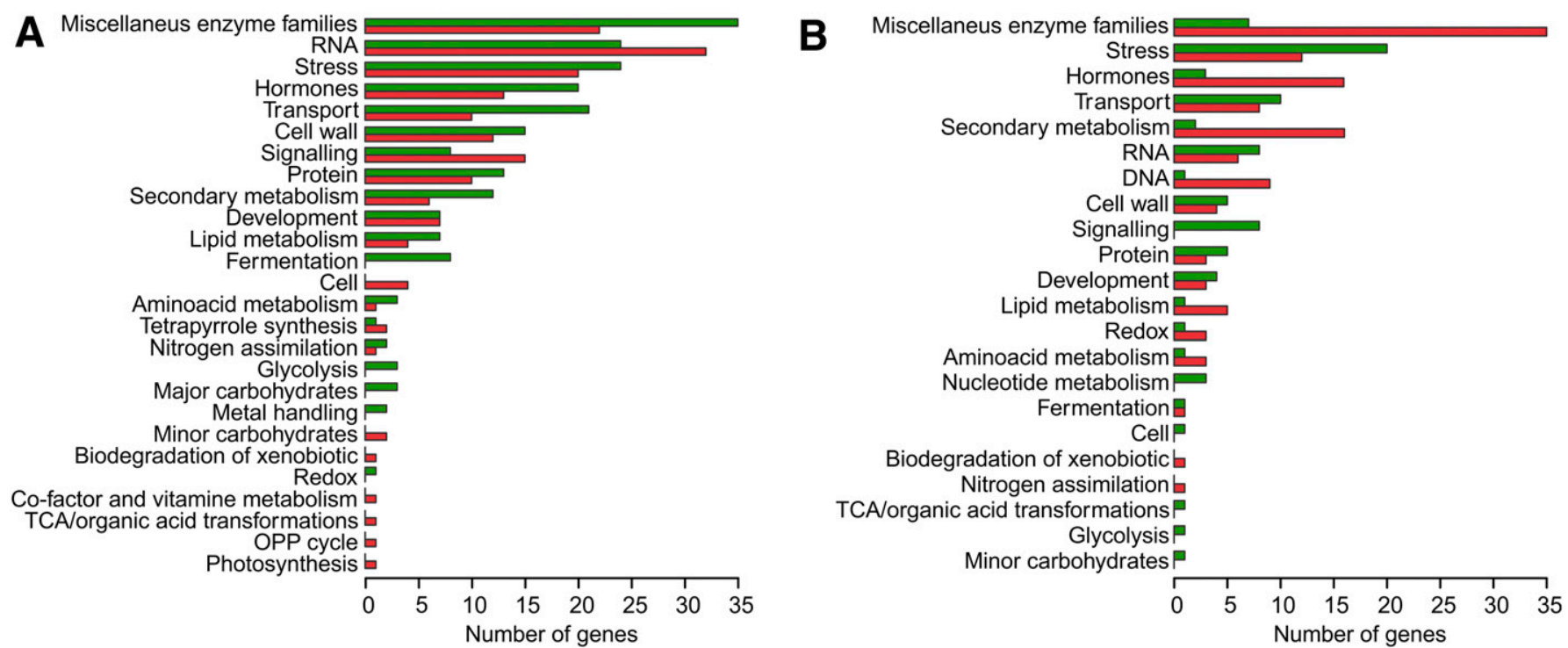

Fig. 5. A MapMan display of common bean modulated genes ( $\log _{2}$ fold-change $\geq 1.0$, false discovery rate $\leq 0.05$ ) according to their assignment to functional categories (BINs). The two sets correspond to the time points at A, 4 days after inoculation (DAI) and B, 10 DAI. BINs colored green are significantly upregulated, whereas those in red are down-regulated genes.

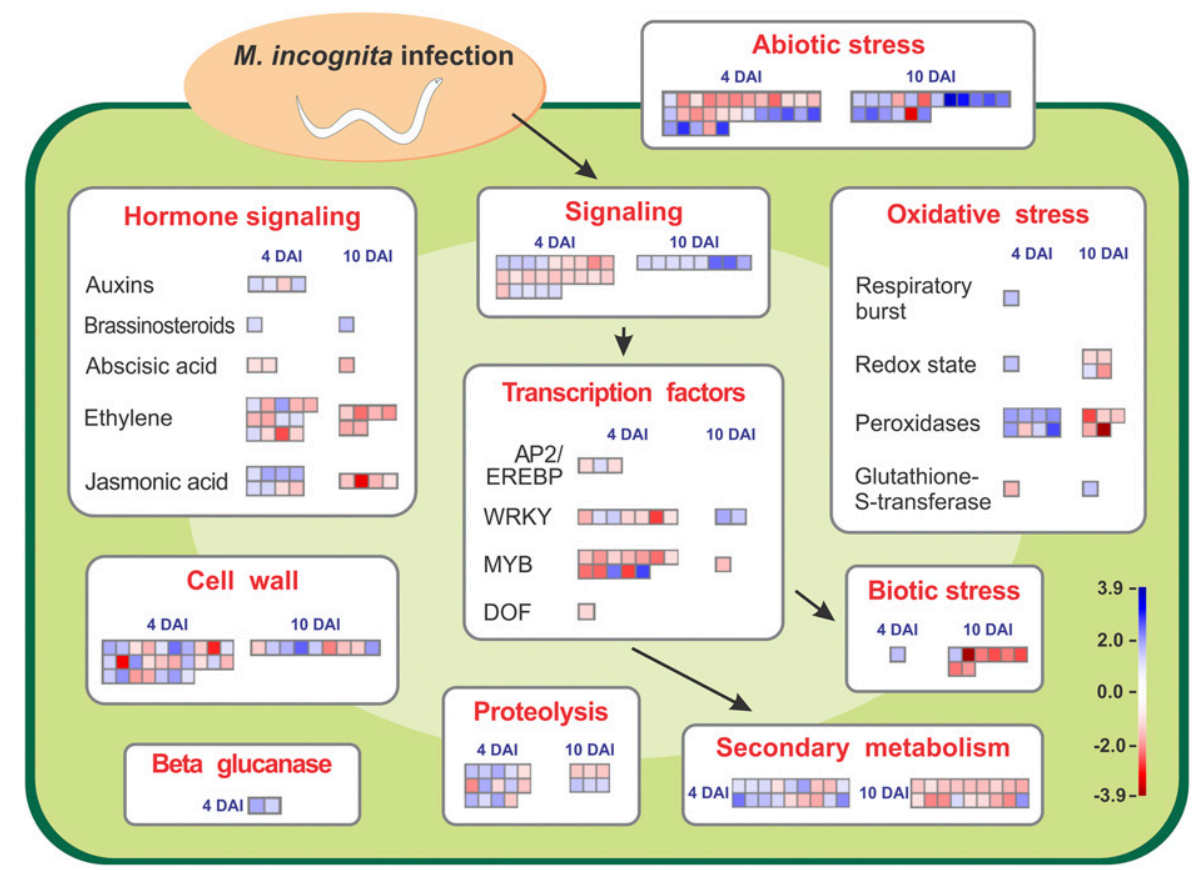

Fig. 6. Display of transcriptional changes in common bean defense-related genes in response to nematode infection. Differentially expressed genes in response to nematode penetration (4 days after inoculation [DAI]) and giant cell development (10 DAI). Only significantly changed genes (log 2 fold-change $\geq 1.0$, false discovery rate $\leq 0.05$ ) were visualized using MapMan software and organized into functional categories (BINs). Blue indicates an increase and red a decrease in gene expression (see color scale on right). Detailed information on each gene and its expression level can be found in Supplementary Tables S2 and S3. 
levels of genes involved in resistance to oxidative stress were detected at $10 \mathrm{DAI}$, possibly due to a reduction in the presence of ROS typical of a compatible reaction. Similarly, ROS have been detected in tomato resistant and susceptible to $M$. incognita, but higher levels were found only to occur in the compatible reaction during the first 48 HAI (Melillo et al. 2006). In general, the repression of the oxidative process is associated with the mitigation of cell damage, but the down-regulation of the associated genes may lead to a compatibility reaction to avoid a hypersensitive response.

In conclusion, the present data lends weight to the argument that a compatible reaction in $P$. vulgaris to $M$. incognita infection is established early during the interaction. Despite the $N$ gene expression triggered by the presence of the nematode, the repression of heat shock protein (required for $N$-mediated host resistance)

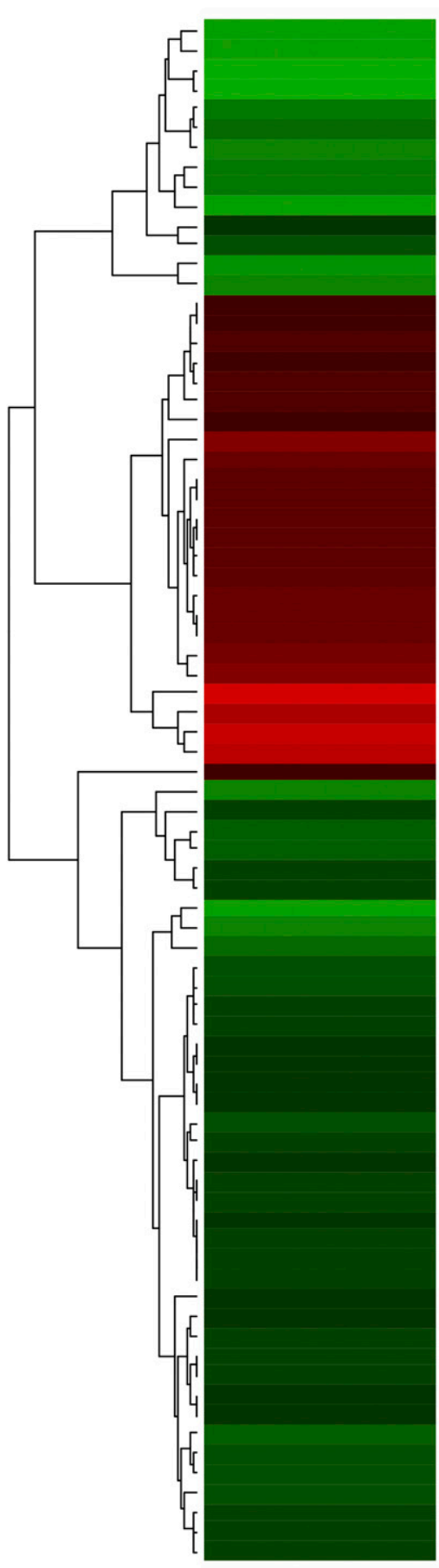

4 DAl
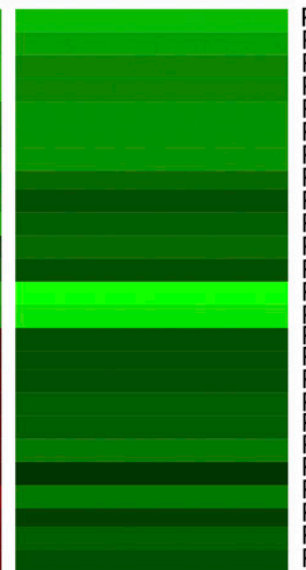

Phvul.005G108200 Abiotic stress/wounding

Phvul.011G110800 Abiotic stress/wounding

Phvul.009G178500 Abiotic stress/light

hvul.004G064700 Regulation of transcription

Phvul.011G110900 Abiotic stress/wounding

Phvul.005G108300 Abiotic stress/wounding

Phvul.005G087300 Not assigned/unknown

Phvul.003G227300 Development/unspecified

Phvul.005G087200 Abiotic stress/wounding

Phvul.004G157100 Regulation of transcription

Phvul.008G005500 Regulation of transcription

Phvul.006G003300 Transport/metal

Phvul.005G108400 Not assigned/unknown

Phvul.005G108000 Abiotic stress/wounding

Phvul.008G013000 Abiotic stress/heat

Phvul.002G166100 Protein/degradation

Phvul.008G167400 ABC transporters and multidrug resistance systems

Phvul.006G135600 Not assigned/unknown

Phvul.011G065000 Abiotic stress/heat

Phvul.003G165800 Miscellaneus enzime families/plastocyanin-like

Phvul.002G082300 Not assigned/unknown

Phvul.003G015600 Cell wall/pectin esterases

Phvul.004G070500 Metabolite transporters at the mitochondrial membrane

Phvul.003G122400 ABC transporters and multidrug resistance systems

Phul.008 167300 ABC transporters and multidrug resistance systems

Phul.008

Phvul.003G287200 Cell wall/degradation

Phvul.005G057400 Not assigned/unknow

Phvul.005G171900 Cell/vesicle transport

Phvul.005G057200 Not assigned/unknown

Phvul.006G079600 Miscellaneus enzime families/glutathione S transferases

Phvul.004G107700 Abiotic stress/heat

Phvul.003G51900 Not assigned/no ontology

Phvul.002G185800 Amino acid metabolism/synthesis

Phvul.004G021200 Miscellaneus enzime families/cytochrome P450

Phvul.002G004100 Cell wall/modification

Phvul.006G147300 Not assigned/no ontology

Phvul.005G022500 Cell wall/degradation

Phvul.004G114300 Miscellaneus enzime families/cytochrome P450

Phvul.009G132200 Not assigned/unknown

Phvul.006G017400 Miscellaneus enzime families/UDP glucosyl and glucoronyl transferases

Phvul.011G105900 Miscellaneus enzime families/peroxidases

Phvul.010G077000 Miscellaneus enzime families/cytochrome P450

Phvul.001G127200 Hormone metabolism/gibberelin

Phvul.009G252900 Not assigned/unknown

Phvul.010G135600 Hormone metabolism/jasmonate

Phvul.003G034000 Not assigned/unknown

Phvul.004G153100 Not assigned/unknown

Phvul 006G129400 Miscellaneus enzime families/peroxidases

Phvul

Phvul.004G170600 ABC transporters and multidrug resistance systems

Phvul.008G015800 Secondary metabolism/flavonoids

Phvul.001G154200 Transport'sulphate

Phvul.001G156900 Lipid metabolism/lipid degradation

Phvul.009G063600 Lipid metabolism/lipid degradation

Phvul.002G314000 Fermentation/aldehyde dehydrogenase

Phvul.002G092200 Not assigned/no ontology

Phvul.002G067700 Transport/peptides and oligopeptides

Phvul.010G135800 Hormone metabolism/jasmonate

Phvul.002G057500 Transport/major intrinsic proteins

Phvul.001G195000 Abiotic stress

Phvul.003G287900 Secondary metabolism/isoprenoids

Phvul.002G326600 Hormone metabolism/ethylene

Phvul.003G022500 Not assigned/unknown

Phvul.011G010600 Protein/degradation

Phvul.005G156800 Hormone metabolism/jasmonate

Phvul.009G108100 Not assigned/unknown

Phvul.001G127400 Hormone metabolism/gibberelin

Phvul.007G020800 Miscellaneus enzime families/UDP glucosyl and glucoronyl transferases

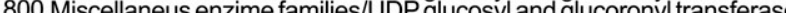
Phvul.008G128700 Miscellaneus enzime families/cytochrome P450

Phvul.009144100 Regulation of transcription

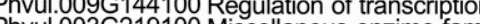

Phvul.003G219100 Miscellaneus enzime families/protease inhibitor

Phvul.003G047100 Secondary metabolism/flavonoids

Phvul.004G135300 Miscellaneus enzime families/short chain dehydrogenase

Phvul.009G187400 Hormone metabolism/gibberelin

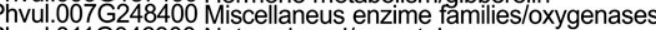

Phvul.011G046300 Not assigned/no ontology

Phvul.003G219200 Miscellaneus enzime families/protease inhibitor

Phvul.007G135600 Hormone metabolism/ethylene

10 DAl

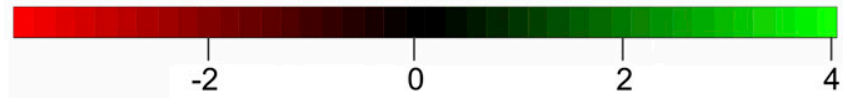

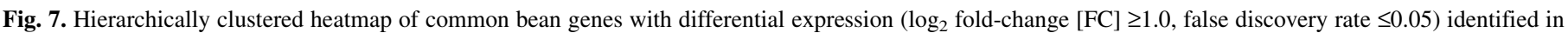

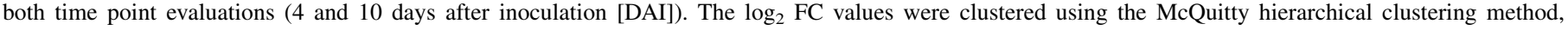

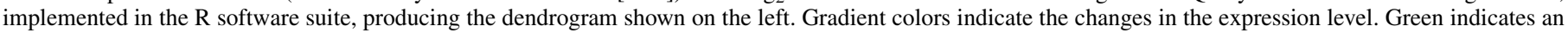

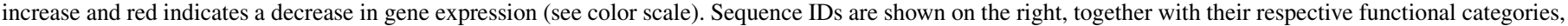
according to the MapMan software. 
results in a lack of ROS accumulation and absence of a hypersensitive response. Furthermore, the host basal response is broken by the repression of the ethylene/jasmonate pathway later in the response, culminating in the establishment of feeding cells, as well pathogen development within the roots, and a continuous compatible process with consequent plant susceptibility.

\section{ACKNOWLEDGMENTS}

L. Santini and C. F. Munhoz received scholarships from the Brazilian institutions $\mathrm{CNPq}$ and FAPESP, respectively. We thank L. E. Aranha Camargo and R. Bessi, Universidade de São Paulo, Brazil, for their helpful comments and suggestions and S. Simmons for proofreading the manuscript.

\section{LITERATURE CITED}

Abad, P., Castagnone-Sereno, P., Rosso, M. N., de Almeida Engler, J., and Favery, B. 2009. Invasion, feeding and development. Pages 163-181 in: Root-knot nematodes. R. N. Perry, M. Moens, and J. L. Starr, eds. CABI, Wallingford.

Abad, P., Gouzy, J., Aury, J.-M., Castagnone-Sereno, P., Danchin, E. G. J., and Deleury, E. 2008. Genome sequence of the metazoan plant-parasitic nematode Meloidogyne incognita. Nat. Biotechnol. 26:909-915.

Abawi, G. S., Mullín, B. A., and Maí, W. F. 2005. Diseases caused by nematodes. Pages 54-57 in: Compendium of Bean Diseases. H. Schwartz, J. R. Steadman, R. Hall, and R. L. Forster, eds. The American Phytopathological Society, St. Paul, MN.

Agrios, G. N. 2005. Plant diseases caused by nematodes. Pages 826-874 in: Plant Pathology. Elsevier Academic Press, Amsterdam, Boston.

Ali, M. A., Wieczorek, K., Kreil, D. P., and Bohlmann, H. 2014. The beet cyst nematode Heterodera schachtii modulates the expression of WRKY transcription factors in syncytia to favour its development in Arabidopsis roots. PLoS One 9:e102360.

Alves, M., Dadalto, S., Gonçalves, A., de Souza, G., Barros, V., and Fietto, L. 2014. Transcription factor functional protein-protein interactions in plant defense responses. Proteomes 2:85-106.

Atamian, H. S., Eulgem, T., and Kaloshian, I. 2012. SIWRKY70 is required for Mi-1-mediated resistance to aphids and nematodes in tomato. Planta 235:299-309.

Barcala, M., García, A., Cabrera, J., Casson, S., Lindsey, K., Favery, B., García-Casado, G., Solano, R., Fenoll, C., and Escobar, C. 2010. Early transcriptomic events in microdissected Arabidopsis nematode-induced giant cells. Plant J. 61:698-712.

Beneventi, M., Silva, O., Sá, M. E., Firmino, A. A., Amorim, R. M., Albuquerque, É. V., da Silva, M. M. C., da Silva, J. P., de Araujo Campos, M., Lopes, M. J. C., Togawa, R. C., Pappas, G. J., Jr., and Grossi-de-Sa, M. F. 2013. Transcription profile of soybean-root-knot nematode interaction reveals a key role of phytohormones in the resistance reaction. BMC Genomics 14:322.

Benjamini, Y., and Hochberg, Y. 1995. Controlling the false discovery rate: A practical and powerful approach to multiple testing. J. R. Stat. Soc., B 57: 289-300.

Bennett, T., van den Toorn, A., Sanchez-Perez, G. F., Campilho, A., Willemsen, V., Snel, B., and Scheres, B. 2010. SOMBRERO, BEARSKIN ${ }_{1}$, and BEARSKIN 2 regulate root cap maturation in Arabidopsis. Plant Cell 22:640-654.

Bhattarai, K. K., Li, Q., Liu, Y., Dinesh-Kumar, S. P., and Kaloshian, I. 2007. The Mi-1-mediated pest resistance requires Hsp90 and Sgt1. Plant Physiol. 144:312-323.

Bhattarai, K. K., Xie, Q.-G., Mantelin, S., Bishnoi, U., Girke, T., Navarre, D. A., and Kaloshian, I. 2008. Tomato susceptibility to root-knot nematodes requires an intact jasmonic acid signaling pathway. Mol. Plant-Microbe Interact. 21:1205-1214.

Brito, J. A., Stanley, J. D., Kaur, R., Cetintas, R., Di Vito, M., Thies, J. A., and Dickson, D. W. 2007. Effects of the Mi-1, N and Tabasco genes on infection and reproduction of Meloidogyne mayaguensis on tomato and pepper genotypes. J. Nematol. 39:327-332.

Broughton, W. J., Hernández, G., Blair, M., Beebe, S., Gepts, P., and Vanderleyden, J. 2003. Beans (Phaseolus spp.)-model food legumes. Plant Soil 252:55-128.

Byrd, D. W., Kirkpatrick, T., and Barker, K. R. 1983. An improved technique for clearing and staining plant tissues for detection of nematodes. J. Nematol. 15: 142-143.

Camilios-Neto, D., Bonato, P., Wassem, R., Tadra-Sfeir, M. Z., Brusamarello-Santos, L. C., Valdameri, G., Donatti, L., Faoro, H., Weiss, V. A., Chubatsu, L. S., Pedrosa, F. O., and Souza, E. M. 2014. Dual RNAseq transcriptional analysis of wheat roots colonized by Azospirillum brasilense reveals up-regulation of nutrient acquisition and cell cycle genes. BMC Genomics 15:378.
Cao, Y., Song, F., Goodman, R. M., and Zheng, Z. 2006. Molecular characterization of four rice genes encoding ethylene-responsive transcriptional factors and their expressions in response to biotic and abiotic stress. J. Plant Physiol. 163:1167-1178.

Caromel, B., and Gebhardt, C. 2011. Breeding for nematode resistance: Use of genomic information. Pages 465-492 in: Genomics and Molecular Genetics of Plant-Nematode Interactions. J. Jones, G. Gheysen, and C. Fenoll, eds. Springer Verlag, Dordrecht, New York.

Casalongué, C. A., Fiol, D. F., París, R., Godoy, A. V., D’Ippólito, S., and Terrile, M. C. 2012. Auxin as part of the wounding response in plants. Pages 115-124 in: Phytohormones and Abiotic Stress Tolerance in Plants. N. A. Khan, R. Nazar, N. Iqbal, and N. A. Anjum, eds. Springer Berlin, Heidelberg.

Chauvin, A., Caldelari, D., Wolfender, J.-L., and Farmer, E. E. 2013. Four 13-lipoxygenases contribute to rapid jasmonate synthesis in wounded Arabidopsis thaliana leaves: A role for lipoxygenase 6 in responses to longdistance wound signals. New Phytol. 197:566-575.

Cheong, Y. H. 2002. Transcriptional profiling reveals novel interactions between wounding, pathogen, abiotic stress, and hormonal responses in Arabidopsis. Plant Physiol. 129:661-677.

CIAT. 2013. A bean revolution in sub-Saharan Africa. International Center for Tropical Agriculture (CIAT). http://www.ard-europe.org/fileadmin/SITE MASTER/content/eiard/Documents/Impact_case_studies_2013/CIAT_-_A_ bean_revolution_in_sub-Saharan_Africa.pdf

Conesa, A., Gotz, S., Garcia-Gomez, J. M., Terol, J., Talon, M., and Robles, M. 2005. Blast2GO: A universal tool for annotation, visualization and analysis in functional genomics research. Bioinformatics 21: 3674-3676.

Coolen, W. A., and D'Herde, C. J. 1972. A Method for the Quantitative Extraction of Nematodes from Plant Tissue. State Nematology and Entomology Research Station. https://books.google.com.br/books?id=C7eDGwAACAAJ\&hl= pt-BR

de Almeida Engler, J., and Gheysen, G. 2012. Nematode-induced endoreduplication in plant host cells: Why and how? Mol. Plant-Microbe Interact. 26:17-24.

Derksen, H., Rampitsch, C., and Daayf, F. 2013. Signaling cross-talk in plant disease resistance. Plant Sci. 207:79-87.

Di Vito, M., Parisi, B., and Catalanol, F. 2004. Effect of population densities of Meloidogyne incognita on common bean. Nematol. Mediterr. 32:81-85.

FAOSTAT. 2013. Food and Agriculture Organization of the United Nations Statistics Division. http://faostat3.fao.org/faostat-gateway/go/to/download/ $\mathrm{T} / \mathrm{TP} / \mathrm{E}$

Ferreira, S., Gomes, L. A. A., Maluf, W. R., Campos, V. P., Carvalho Filho, J. L. S., and Santos, D. C. 2010. Resistance of dry bean and snap bean cultivars to root-knot nematodes. HortScience 45:320-322.

Gao, L., Tu, Z., Millett, B. P., and Bradeen, J. M. 2013. Insights into organspecific pathogen defense responses in plants: RNA-seq analysis of potato tuber-Phytophthora infestans interactions. BMC Genomics 14:340.

Gheysen, G., and Mitchum, M. G. 2011. How nematodes manipulate plant development pathways for infection. Curr. Opin. Plant Biol. 14:415-421.

Gosling, P. J. 2005. Dictionary of Parasitology. CRC Press, Boca Raton, FL.

Grennan, A. K. 2008. Ethylene response factors in jasmonate signaling and defense response. Plant Physiol. 146:1457-1458.

Gutierrez, O. A., Wubben, M. J., Howard, M., Roberts, B., Hanlon, E., and Wilkinson, J. R. 2009. The role of phytohormones ethylene and auxin in plant-nematode interactions. Russ. J. Plant Physiol. 56:1-5.

Hirao, T., Fukatsu, E., and Watanabe, A. 2012. Characterization of resistance to pine wood nematode infection in Pinus thunbergii using suppression subtractive hybridization. BMC Plant Biol. 12:13.

Hooper, D. J. 1986. Extration of free-living stages from soil. Pages 5-30 in: Laboratory Methods for Work with Plant and Soil Nematodes. Her Majesty's Stationery Office, London.

Hutangura, P., Mathesius, U., Jones, M. G. K., and Rolfe, B. G. 1999. Auxin induction is a trigger for root gall formation caused by root-knot nematodes in white clover and is associated with the activation of the flavonoid pathway. Aust. J. Plant Physiol. 26:221.

IAPAR. 2004. IPR Saracura: Cultivar de feijão do grupo carioca de alta produtividade, ampla adaptação e excelente qualidade comercial e culinária. Instituto Agronômico do Paraná. http://www.iapar.br/arquivos/File/zip_pdf/ iprsaracura.pdf

Ibrahim, H. M., Hosseini, P., Alkharouf, N. W., Hussein, E. H., Gamal El-Din, A. E. K. Y., Aly, M. A., and Matthews, B. F. 2011. Analysis of gene expression in soybean (Glycine max) roots in response to the root knot nematode Meloidogyne incognita using microarrays and KEGG pathways. BMC Genomics12:220.

Jammes, F., Lecomte, P., de Almeida-Engler, J., Bitton, F., Martin-Magniette, M.-L., Renou, J. P., Abad, P., and Favery, B. 2005. Genome-wide expression profiling of the host response to root-knot nematode infection in Arabidopsis. Plant J. 44:447-458. 
Ji, H., Gheysen, G., Denil, S., Lindsey, K., Topping, J. F., Nahar, K., Haegeman, A., De Vos, W. H., Trooskens, G., Van Criekinge, W., De Meyer, T., and Kyndt, T. 2013. Transcriptional analysis through RNA sequencing of giant cells induced by Meloidogyne graminicola in rice roots. J. Exp. Bot. 64:3885-3898.

Jones, M. G. K., and Goto, D. B. 2011. Root-knot nematodes and giant cells. Pages 82-100 in: Genomics and Molecular Genetics of Plant-Nematode Interactions. J. Jones, G. Gheysen, and C. Fenoll, eds. Springer Verlag, New York.

Kiewnick, S., Dessimoz, M., and Franck, L. 2009. Effects of the Mi- 1 and the $N$ root-knot nematode-resistance gene on infection and reproduction of Meloidogyne enterolobii on tomato and pepper cultivars. J. Nematol. 41:134-139.

Klink, V. P., Overall, C. C., Alkharouf, N. W., MacDonald, M. H., and Matthews, B. F. 2007. Laser capture microdissection (LCM) and comparative microarray expression analysis of syncytial cells isolated from incompatible and compatible soybean (Glycine max) roots infected by the soybean cyst nematode (Heterodera glycines). Planta 226:1389-1409.

Kyndt, T., Vieira, P., Gheysen, G., and de Almeida-Engler, J. 2013. Nematode feeding sites: Unique organs in plant roots. Planta 238:807-818.

Li, R., Rashotte, A., Singh, N., Weaver, D., Lawrence, K., and Locy, R. 2015. Integrated signaling networks in plant responses to sedentary endoparasitic nematodes: A perspective. Plant Cell Rep. 34:5-22.

Li, X., Bai, T., Li, Y., Ruan, X., and Li, H. 2013. Proteomic analysis of Fusarium oxysporum $\mathrm{f}$. sp. cubense tropical race 4-inoculated response to Fusarium wilts in the banana root cells. Proteome Sci. 11:41.

Liu, Y., Burch-Smith, T., Schiff, M., Feng, S., and Dinesh-Kumar, S. P. 2004. Molecular chaperone $\mathrm{Hsp} 90$ associates with resistance protein $\mathrm{N}$ and its signaling proteins SGT1 and Rar1 to modulate an innate immune response in plants. J. Biol. Chem. 279:2101-2108.

Liu, Z., Zhang, S., Sun, N., Liu, H., Zhao, Y., Liang, Y., Zhang, L., and Han, Y. 2015. Functional diversity of jasmonates in rice. Rice (N.Y.) 8:42.

Livak, K. J., and Schmittgen, T. D. 2001. Analysis of relative gene expression data using real-time quantitative PCR and the $2^{-\Delta \Delta C T}$ method. Methods 25 : 402-408.

Lohse, M., Nagel, A., Herter, T., May, P., Schroda, M., Zrenner, R., Tohge, T., Fernie, A. R., Stitt, M., and Usadel, B. 2014. Mercator: A fast and simple web server for genome scale functional annotation of plant sequence data. Plant Cell Environ. 37:1250-1258.

Lorenzo, O., Piqueras, R., Sánchez-Serrano, J. J., and Solano, R. 2003. Ethylene response factor 1 integrates signals from ethylene and jasmonate pathways in plant defense. Plant Cell 15:165-178.

Mantelin, S., Bhattarai, K. K., Jhaveri, T. Z., and Kaloshian, I. 2013. Mi-1mediated resistance to Meloidogyne incognita in tomato may not rely on ethylene but hormone perception through ETR3 participates in limiting nematode infection in a susceptible host. PLoS One 8:e63281.

Margaria, P., Abbà, S., and Palmano, S. 2013. Novel aspects of grapevine response to phytoplasma infection investigated by a proteomic and phospho-proteomic approach with data integration into functional networks. BMC Genomics 14:38.

McQuitty, L. L. 1966. Similarity analysis by reciprocal pairs for discrete and continuous data. Educ. Psychol. Meas. 26:825-831.

Melillo, M. T., Leonetti, P., Bongiovanni, M., Castagnone-Sereno, P., and Bleve-Zacheo, T. 2006. Modulation of reactive oxygen species activities and $\mathrm{H}_{2} \mathrm{O}_{2}$ accumulation during compatible and incompatible tomato-rootknot nematode interactions. New Phytol. 170:501-512.

Milligan, S. B., Bodeau, J., Yaghoobi, J., Kaloshian, I., Zabel, P., and Williamson, V. M. 1998. The root knot nematode resistance gene $M i$ from tomato is a member of the leucine zipper, nucleotide binding, leucine-rich repeat family of plant genes. Plant Cell 10:1307-1319.

Mullin, B. A., Abawi, G. S., and Pastor-Corrales, M. A. 1991. Modification of resistance expression of Phaseolus vulgaris to Meloidogyne incognita by elevated soil temperatures. J. Nematol. 23:182-187.

Munhoz, C. F., Santos, A. A., Arenhart, R. A., Santini, L., Monteiro-Vitorello, C. B., and Vieira, M. L. C. 2015. Analysis of plant gene expression during passion fruit-Xanthomonas axonopodis interaction implicates lipoxygenase 2 in host defence: Gene expression during passion fruit-Xanthomonas axonopodis interaction. Ann. Appl. Biol. 167:135-155.

Nahar, K., Kyndt, T., De Vleesschauwer, D., Hofte, M., and Gheysen, G. 2011. The jasmonate pathway is a key player in systemically induced defense against root knot nematodes in rice. Plant Physiol. 157:305-316.

Oostenbrink, M. 1966. Major Characteristics of the Relation Between Nematodes and Plants, 4th Ed. Mendelingen Landbouwhogeschool Wageningen, Wageningen. https://books.google.com.br/books?id=3GmPtgAACAAJ\&hl= pt-BR

Ozalvo, R., Cabrera, J., Escobar, C., Christensen, S. A., Borrego, E. J., Kolomiets, M. V., Castresana, C., Iberkleid, I., and Brown Horowitz, S. 2014. Two closely related members of Arabidopsis 13-lipoxygenases (13LOXs), LOX3 and LOX4, reveal distinct functions in response to plantparasitic nematode infection. Mol. Plant Pathol. 15:319-332.

Perry, R. N., and Moens, M. 2011. Introduction to plant-parasitic nematodes: Modes of parasitism. Pages 3-20 in: Genomics and Molecular Genetics of
Plant-Nematode Interactions. J. Jones, G. Gheysen, and C. Fenoll, eds. Springer Verlag, New York

Puthoff, D. P., Ehrenfried, M. L., Vinyard, B. T., and Tucker, M. L. 2007. GeneChip profiling of transcriptional responses to soybean cyst nematode, Heterodera glycines, colonization of soybean roots. J. Exp. Bot. 58:3407-3418.

Quentin, M., Abad, P., and Favery, B. 2013. Plant parasitic nematode effectors target host defense and nuclear functions to establish feeding cells. Front. Plant Sci. 4:53.

R Core Team. 2012. R: A language and environment for statistical computing. R Foundation for Statistical Computing, Vienna, Austria. https://www. r-project.org/

Ramakers, C., Ruijter, J. M., Deprez, R. H. L., and Moorman, A. F. 2003. Assumption-free analysis of quantitative real-time polymerase chain reaction (PCR) data. Neurosci. Lett. 339:62-66.

Robinson, M. D., and Smyth, G. K. 2008. Small-sample estimation of negative binomial dispersion, with applications to SAGE data. Biostatistics 9:321-332.

Saini, S., Sharma, I., Kaur, N., and Pati, P. K. 2013. Auxin: A master regulator in plant root development. Plant Cell Rep. 32:741-757.

Saka, V. W. 1990. Evaluation of common bean (Phaseolus vulgaris), groundnut (Arachis hypogea) and pigeon pea (Cajanus cajan) for resistance to root-knot nematodes (Meloidogyne spp.). Field Crops Res. 23:39-44.

Santos, L. N. S., Alves, F. R., Belan, L. L., Cabral, P. D. S., Matta, F. P., Jesus Junior, W. C., and Moraes, W. B. 2012. Damage quantification and reaction of bean genotypes (Phaseolus vulgaris L.) to Meloidogyne incognita race 3 and $M$. javanica. Summa Phytopathol. 38:24-29.

Schmutz, J., McClean, P. E., Mamidi, S., Wu, G. A., Cannon, S. B., and Grimwood, J. 2014. A reference genome for common bean and genomewide analysis of dual domestications. Nat. Genet. 46:707-713.

Seo, E., Choi, D., and Choi. 2015. Functional studies of transcription factors involved in plant defenses in the genomics era. Brief. Funct. Genomics 4:260-267.

Starr, J. L., Bridge, J., and Cook, R. 2002. Resistance to plant-parasitic nematodes: History, current use and future potencial. Pages 1-22 in: Plant Resistance to Parasitic Nematodes. J. L. Starr, R. Cook, and J. Bridge, eds. CABI Publishing, New York.

Supek, F., Bošnjak, M., Škunca, N., and Šmuc, T. 2011. REVIGO summarizes and visualizes long lists of gene ontology terms. PLoS One 6:e21800.

Sydenham, G. M., McSorley, R., and Dunn, R. A. 1997. Effects of temperature on resistance in Phaseolus vulgaris genotypes and on development of Meloidogyne species. J. Nematol. 29:90-103.

Szakasits, D., Heinen, P., Wieczorek, K., Hofmann, J., Wagner, F., Kreil, D. P., Sykacek, P., Grundler, F. M. W., and Bohlmann, H. 2009. The transcriptome of syncytia induced by the cyst nematode Heterodera schachtii in Arabidopsis roots. Plant J. 57:771-784.

Thimm, O., Bläsing, O., Gibon, Y., Nagel, A., Meyer, S., Krüger, P., Selbig, J., Müller, L. A., Rhee, S. Y., and Stitt, M. 2004. MapMan: A user-driven tool to display genomics data sets onto diagrams of metabolic pathways and other biological processes. Plant J. 37:914-939.

Tucker, M. L., Burke, A., Murphy, C. A., Thai, V. K., and Ehrenfried, M. L. 2007. Gene expression profiles for cell wall-modifying proteins associated with soybean cyst nematode infection, petiole abscission, root tips, flowers, apical buds, and leaves. J. Exp. Bot. 58:3395-3406.

Usadel, B., Nagel, A., Thimm, O., Redestig, H., Blaesing, O. E., Palacios-Rojas, N., Selbig, J., Hannemann, J., Piques, M. C., Steinhauser, D., Scheible, W.-R., Gibon, Y., Morcuende, R., Weicht, D., Meyer, S., and Stitt, M. 2005. Extension of the visualization tool MapMan to allow statistical analysis of arrays, display of corresponding genes, and comparison with known responses. Plant Physiol. 138:1195-1204.

Van Loon, L. C., Geraats, B. P. J., and Linthorst, H. J. M. 2006. Ethylene as a modulator of disease resistance in plants. Trends Plant Sci. 11:184-191.

Vos, P., Simons, G., Jesse, T., Wijbrandi, J., Heinen, L., Hogers, R., Frijters, A., Groenendijk, J., Diergaarde, P., Reijans, M., Fierens-Onstenk, J., Both, M., Peleman, J., Liharska, T., Hontelez, J., and Zabeau, M. 1998. The tomato $\mathrm{Mi}-1$ gene confers resistance to both root-knot nematodes and potato aphids. Nat. Biotechnol. 16:1365-1369.

Warnes, G. R., Bolker, B., Bonebakker, L., Gentleman, R., Liaw, W. H. A., Lumley, T., Magnusson, A., Moeller, S., Schwartz, M., and Venables, B. 2014. gplots: Various $\mathrm{R}$ programming tools for plotting data. $\mathrm{R}$ package version 2.14.2. https://cran.r-project.org/web/packages/gplots/index.html

Whitham, S., Dinesh-Kumar, S. P., Choi, D., Hehl, R., Corr, C., and Baker, B. 1994. The product of the tobacco mosaic virus resistance gene $N$ : Similarity to toll and the interleukin-1 receptor. Cell 78:1101-1115.

Wieczorek, K., Golecki, B., Gerdes, L., Heinen, P., Szakasits, D., Durachko, D. M., Cosgrove, D. J., Kreil, D. P., Puzio, P. S., Bohlmann, H., and Grundler, F. M. W. 2006. Expansins are involved in the formation of nematode-induced syncytia in roots of Arabidopsis thaliana. Plant J. 48:98-112.

Xu, D.-L., Long, H., Liang, J.-J., Zhang, J., Chen, X., Li, J.-L., Pan, Z.-F., Deng, G.-B., and Yu, M.-Q. 2012. De novo assembly and characterization of the root transcriptome of Aegilops variabilis during an interaction with the cereal cyst nematode. BMC Genomics 13:133. 